Fakultät III

Wirtschaftswissenschaften, Wirtschaftsinformatik und Wirtschaftsrecht

Volkswirtschaftliche Diskussionsbeiträge

Discussion Papers in Economics

No. $176-15$

December 2015

Thomas Eichner $\cdot$ Rüdiger Pethig

Self-enforcing environmental agreements and trade in fossil energy deposits 
Universität Siegen

Fakultät III

Wirtschaftswissenschaften, Wirtschaftsinformatik und Wirtschaftsrecht

Fachgebiet Volkswirtschaftslehre

Hölderlinstraße 3

D-57068 Siegen

Germany

http://www.wiwi.uni-siegen.de/vwl/

ISSN 1869-0211

Available for free from the University of Siegen website at

http://www.wiwi.uni-siegen.de/vwl/research/diskussionsbeitraege/

Discussion Papers in Economics of the University of Siegen are indexed in RePEc and can be downloaded free of charge from the following website:

http://ideas.repec.org/s/sie/siegen.html 


\title{
Self-enforcing environmental agreements and trade in fossil energy deposits*
}

\author{
Thomas Eichner \\ Department of Economics, University of Hagen \\ Rüdiger Pethig \\ Department of Economics, University of Siegen
}

\begin{abstract}
This paper analyzes the formation of self-enforcing climate agreements, or stable climate coalitions, when all countries have the option to fight climate change by purchasing (the right to extract) fossil-energy deposits. First, we consider the stand-alone deposit purchase policy and then combine that policy with the option to tax or subsidize the supply of deposits. In either case, coalitions of any size turn out to buy deposits while the non-cooperative countries do not. In case of the standalone deposit purchase policy either no coalition is stable or the grand coalition is the only stable coalition. If the two-instrument policy is implemented, all countries inside and outside the coalition are better off than in case of the stand-alone deposit policy, but the conditions for stable grand coalitions are more favorable under the stand-alone deposit policy than under the two-instrument policy due to weaker free-rider incentives.
\end{abstract}

JEL classification: $\quad$ C72, Q38, Q58

Key words: climate coalition, deposit, fuel, Nash, self-enforcing IEA

*Eichner: Department of Economics, University of Hagen, Universitätsstr. 41, 58097 Hagen, Germany, email: thomas.eichner@fernuni-hagen.de; Pethig: Department of Economics, University of Siegen, Hölderlinstr. 3, 57068 Siegen, Germany, pethig@vwl.wiwi.uni-siegen.de. 


\section{The problem}

Scientific evidence suggests that stabilizing the world climate at safe levels requires a massive reduction of greenhouse gas emissions, notably carbon emissions from burning fossil fuels. That calls for an effective and encompassing international environmental agreement (IEA). The first legally binding IEA on climate change, the Kyoto Protocol, achieved little more than business as usual, and it is unclear whether the ongoing negotiations towards a broad and deep follow-up agreement will be successful. Therefore, improving our understanding of the conditions for effective IEAs is important. One of the key issues not yet well understood is how the choice of climate policy instruments influences the conditions for the formation of stable and effective climate conditions.

There is a large literature studying self-enforcing environmental agreements. The early workhorse model of Barrett (1994), Hoel (1992), Carraro and Siniscalco (1993) and further analyzed by Diamantoudi and Sartzetakis (2006) and Rubio and Ulph (2006) has been extended into various directions. E.g. Hoel and Schneider (1997) introduce transfer schemes in the coalition formation process, Finus and Pintassilgo (2013) study uncertainty and learning, and Eichner and Pethig (2013, 2015) extend that model by competitive markets and international trade. This literature is quite pessimistic about large and deep stable climate coalitions and finds that whenever the gains from cooperation would be large stable coalitions achieve only little. An exception is Eichner and Pethig (2015) who show that international trade may render the grand coalition stable when countries use emission taxes.

The prevailing approach to climate policy both in practice and in the environmentaleconomics literature is the reduction of carbon emissions via emission caps, emission taxes or cap-and-trade systems. Supply-side policies are much less studied and implemented. The present paper focuses on a special supply-side climate policy, the international trade in (the right to extract) fossil energy deposits. The idea is to mitigate climate change through buying and preserving some of those deposits that would otherwise have been exploited. While Bohm (1992) questions the usefulness of that policy, if it stands alone, ${ }^{1}$ Harstad (2012) points out that a market for fossil-energy deposits and other minerals already exists between countries and international companies as well as between countries First, we assume that the fuel market and deposit market equilibrate simultaneously. In contrast, Harstad (2012) considers a sequential game at which the deposit market clears prior to the fuel market.. Here we follow Harstad in investigating the utilization of such a market as an

\footnotetext{
${ }^{1}$ Bohm (1992) considers the stand-alone deposit purchase policy as "rather farfetched", because it is very costly and increases the fuel price. The practicability and political viability of trading fossil energy deposits is a serious issue which the present paper disregards, however. Our analysis aims to improve our understanding of the economics of deposit trading.
} 
instrument of international climate policy. Specifically, we aim to explore the formation and effectiveness of self-enforcing IEAs, when there is a world market for deposits and the governments' climate policy takes the form of purchasing deposits with the intention to prevent their exploitation.

We envisage a world of symmetric countries all of which extract, trade, and consume fossil energy, called fuel for short. All countries suffer from climate damage caused by global carbon emissions that are proportional to global fuel consumption. In that analytical framework we investigate the conditions under which IEAs are self-enforcing when all countries inside and outside the climate coalition have the option to sell and/or buy deposits.

To our knowledge, the only analytical studies of the deposit purchase policy are Bohm (1993) and Harstad (2012, 2010). Bohm (1993) considers a given sub-global coalition that unilaterally aims to implement a predetermined global emission-reduction goal either by reducing its fuel demand or by a special mix of capping its fuel demand and purchasing deposits. The present paper neither sets an emission-reduction goal nor aims to compare the cost-effectiveness of demand-side policies and (mixed) supply-side policies. Harstad $(2012,2010)$ analyzes coalition formation in a world economy of heterogeneous countries where global carbon emissions generate climate damage. A sub-global coalition mitigates climate damage by means of the purchase of deposits combined with caps on the demand and supply of fuel. Harstad's remarkable result is that when deposits are traded between the coalition and producers any coalition size may be stable (see Harstad 2010, Proof of Proposition 5). ${ }^{2}$ Conceptually, we adopt Harstad's analytical framework, but deviate from it in various ways.

First, we take a different approach to modeling the deposit market. While Harstad conceives of that market as a set of bilateral deposit trades that exhaust all mutual advantages, we model the deposit market in a standard way with a uniform price. Second, we do not adopt Harstad's three-instrument policy design of deposit purchases and caps on the demand and supply of fuel. In addition, in Harstad (2012, 2010) non-coalition members are inactive, i.e. they do not have any climate policy. Instead, we investigate two different supply-side policies. One is the stand-alone deposit purchase policy and the other is a combination of that policy with a tax or subsidy on domestic deposit supply. All countries set these policy instruments regardless of whether they are in the coalition or not. Third, while Harstad $(2012,2010)$ assumes that the damage function is linear, we follow Barrett (1994), Diamantoudi and Sartzetakis (2006) and Rubio and Ulph (2006) and study coalition formation for quadratic damage. Fourth, we assume that the fuel market and deposit market

\footnotetext{
${ }^{2}$ Harstad (2010) is the discussion paper version of Harstad (2012). In some parts, especially in the section that describes coalition formation, Harstad (2010) is more detailed than Harstad (2012).
} 
equilibrate simultaneously. In contrast, Harstad (2012, 2010) considers a sequential game at which the deposit market clears prior to the fuel market. In sharp contrast to Harstad $(2012,2010)$ we find that either no coalition is stable or the grand coalition is the only stable coalition.

After having set up the analytical framework in Section 2, we study in Section 3.1 the game between the coalition and the non-cooperative fringe countries. The coalition plays Nash against the fringe countries and each fringe country plays Nash against the coalition and all fellow fringe countries. We characterize the equilibrium allocations for alternative coalition sizes (Proposition 1) and show among other things that coalition countries sell and buy, whereas fringe countries sell but do not buy deposits. The information how the countries' equilibrium payoffs (welfares) depend on the coalition size is needed for examining the coalition stability in Section 3.2. There we derive necessary and sufficient conditions for the stability of the grand coalition (Proposition 2) and also show that either no stable coalitions exists or the grand coalition is the only stable coalition (Proposition 3).

The analysis of Section 3 is based on the assumption that profit-maximizing extraction firms determine the supply of deposits. In practice, governments may want to consider the option of taxing or subsidizing the supply of domestic deposits in addition to purchasing deposits. We deal with that policy-mix in Section 4. In the corresponding Nash equilibrium with a coalition of given size both fringe countries and coalition countries improve their welfare. Turning to the stability issue we show that the fringe countries' free-riding incentives increases which renders the grand coalition unstable more unlikely compared to the regime without subsidy.

\section{The analytical framework}

\subsection{Competitive equilibrium with given demand for deposits}

We consider ${ }^{3} n$ identical countries each of which produces a standard consumption good (quantity $x_{i}^{s}$ ) and fossil energy (quantity $e_{i}^{s}$ ), called fuel for short, from domestic deposits. Each country uses its endowment $\bar{r}$ of a composite input to produce both goods according to the simple production functions $x_{i}^{s}=r_{x}$ and $e_{i}^{s}=\left(\frac{2}{\alpha} r_{e}\right)^{\frac{1}{2}}$. $\alpha$ is a positive constant and $r_{x}$ and $r_{e}$ are the respective inputs. Imposing full employment, $r_{e}+r_{x}=\bar{r}$, we conveniently

\footnotetext{
${ }^{3}$ We keep the description and discussion of the analytical framework short, because, essentially, our basic model is that of Harstad (2012).
} 
represent the supply side of each country's economy by the transformation function ${ }^{4}$

$$
x_{i}^{s}=T\left(e_{i}^{s}\right)=\bar{r}-K\left(e_{i}^{s}\right) \quad \text { with } K\left(e_{i}^{s}\right):=\frac{\alpha}{2}\left(e_{i}^{s}\right)^{2} .
$$

$K\left(e_{i}^{s}\right)$ is the cost of extracting the amount $e_{i}^{s}$ of fuel expressed in units of the productive factor. Following Harstad (2012, p. 85), we interpret the extraction cost function $K$ as a function that implicitly orders country $i$ 's (small) deposits according to their extraction costs such that $K_{e_{i}^{s}}\left(e_{i}^{s}\right)$ ". . is a mapping from country $i$ 's deposits, ordered according to costs, to the marginal extraction cost of these deposits." 5 The greenhouse gas carbon dioxide is generated proportional to fuel consumption. With a suitable choice of units, $e_{i}^{d}$ represents both fuel consumption and carbon emissions. Global emissions cause the climate damage

$$
D\left(\sum_{j} e_{j}^{d}\right):=\frac{\delta}{2}\left(\sum_{j} e_{j}^{d}\right)^{2} \quad(\delta>0 \text { and constant })
$$

in each country. The representative consumer of country $i$, consumer $i$ for short, derives the utility

$$
B\left(e_{i}^{d}\right):=a e_{i}^{d}-\frac{b}{2}\left(e_{i}^{d}\right)^{2} \quad(a, b>0 \text { and constant })
$$

from consuming fuel, the utility $x_{i}^{d}$ from consuming good $X$, and suffers from climate damage (2). Her overall utility is

$$
u_{i}=B\left(e_{i}^{d}\right)+x_{i}^{d}-D\left(\sum_{j} e_{j}^{d}\right) .
$$

The demand for the consumption good is $x_{i}^{d}=y_{i}-p_{e} e_{i}^{d}, p_{e}$ is the fuel price, $p_{x} \equiv 1$ is the price of the consumption good ${ }^{6}$ and $y_{i}=T\left(e_{i}^{s}\right)+p_{e} e_{i}^{s}$ is income in terms of the consumption good in the no-policy regime. Consumer $i$ takes $y_{i}, p_{e}, p_{x}$ and the prevailing climate damage as given and maximizes (4) with respect to $e_{i}^{d}$. The maximization yields $B_{e_{i}^{d}}\left(e_{i}^{d}\right)=p_{e}$ and the fuel demand function

$$
e_{i}^{d}=E^{d i}\left(p_{e}\right):=B_{e_{i}^{d}}^{-1}\left(p_{e}\right)=\frac{a-p_{e}}{b},
$$

where $B_{e_{i}^{d}}^{-1}$ is the inverse of the marginal benefit function $B_{e_{i}^{d}}$. Each country $i$ hosts a firm, firm $i$ for short, that extracts the amount $e_{i}^{s}$ of fuel and sells it on the fuel market at price $p_{e}$. In addition, it offers the amount $z_{i}^{s}$ of 'fuel in situ' on the deposit market ${ }^{7}$ at price $p_{z}$.

\footnotetext{
${ }^{4}$ Upper case letters denote functions and subscripts attached to them denote derivatives.

${ }^{5}$ We characterize a deposit by the amount of fossil fuel in the ground that can be extracted and by the cost of extracting that fuel.

${ }^{6}$ Due to the simple production function of the consumption good, $x_{i}^{s}=r_{x}$, the factor price is also unity.

${ }^{7}$ In the present section we assume that firm $i$ is entitled to sell (the right to exploit) deposits. An alternative assumption is that governments own the deposits and are entitled to sell (the right to exploit) the country's deposits. We will take up the issue of government control on supplying deposits in Section 4 below. Note also that the deposit supply of price-taking welfare maximizing governments is equivalent to the deposit supply of profit-maximizing price-taking firms.
} 
More precisely, the item the firm offers on the deposit market is the right to exploit specific deposits that store the amount $z_{i}^{s}$ of fuel. To avoid clumsy wording we refer to $z_{i}^{s}$ and $z_{i}^{d}$ as deposits supplied and demanded, respectively.

Next, we specify the deposits firm $i$ either exploits, or sells unexploited, or leaves in the ground unsold. To that end, suppose for the time being there is no deposit market. Then the firm's maximization of profit $T\left(e_{i}^{s}\right)+p_{e} e_{i}^{s}$ yields the first-order condition $K_{e_{i}^{s}}\left(e_{i}^{s}\right)=p_{e}$ and the fuel supply function

$$
e_{i}^{s}=\Phi^{s i}\left(p_{e}\right):=K_{e_{i}^{s}}^{-1}\left(p_{e}\right)=\frac{p_{e}}{\alpha},
$$

where $K_{e_{i}^{s}}^{-1}\left(p_{e}\right)$ is the inverse of the marginal extraction cost function $K_{e_{i}^{s}}$. In terms of deposit language, (6) means that firm $i$ exploits all deposits with extraction costs $K_{e_{i}^{s}}\left(p_{e}\right) \leq p_{e}$. The firm obviously has an incentive to offer deposits with extraction costs $K_{e_{i}^{s}}\left(p_{e}\right)>p_{e}$, which it would not exploit in the absence of deposit trading. However, countries that consider buying deposits do so for one and only one reason: to reduce total fuel extraction and consumption. That is, they seek to prevent the extraction of fuel that is stored in those deposits which the extraction firms would have exploited in the absence of deposit trading. They therefore only buy deposits with extraction $\operatorname{costs} K_{e_{i}^{s}}\left(p_{e}\right) \leq p_{e}$, no matter in which country the deposit-selling firm is located. Since all firms observe that constraint, the fuel supply is

$$
e_{i}^{s}=\Phi^{s i}\left(p_{e}\right)-z_{i}^{s}=\frac{p_{e}}{\alpha}-z_{i}^{s},
$$

when firm $i$ offers the deposits $z_{i}^{s}$ for sale.

Each firm generates a profit from producing and selling fuel and receives the revenues $p_{z} z_{i}^{s}$ from selling the deposits $z_{i}^{s}$. Firm $i$ 's total income therefore is

$$
p_{e}\left[\Phi^{s i}-z_{i}^{s}\right]-K\left[\Phi^{s i}\left(p_{e}\right)-z_{i}^{s}\right]+p_{z} z_{i}^{s} .
$$

Taking $p_{e}$ and $p_{z}$ as given, it maximizes (8) with respect to $z_{i}^{s}$, and thus determines its fuel supply as

$$
K_{e_{i}^{s}}\left(p_{e}\right)=p_{e}-p_{z} \quad \text { or } \quad e_{i}^{s}=E^{s i}\left(p_{e}-p_{z}\right):=K_{e_{i}^{s}}^{-1}\left(p_{e}-p_{z}\right)=\frac{p_{e}-p_{z}}{\alpha} .
$$

Combining (7) and (9) leads to

$$
z_{i}^{s}=\Phi^{s i}\left(p_{e}\right)-E^{s i}\left(p_{e}-p_{z}\right)=\frac{p_{z}}{\alpha} .
$$

The simultaneous determination of the supply functions (9) for fuel and (10) for deposits demonstrates the strong interdependence of the markets for deposits and fuel. In view of the fuel demand (5) and the fuel supply (9) the fuel-market clearing condition is

$$
\sum_{j} E^{d j}\left(p_{e}\right)=\sum_{j} E^{s j}\left(p_{e}-p_{z}\right) \quad \text { or } \quad \frac{a-p_{e}}{b}=\frac{p_{e}-p_{z}}{\alpha} .
$$


Equation (10) specifies each firm's deposit supply. The demand for deposits, $z_{i}^{d}$, is a policy parameter of country $i$ 's government. In game theoretic language, $z_{i}^{d}$ is country $i$ 's strategy. Under the preliminary assumption that some (feasible) profile $\left(z_{1}^{d}, \ldots, z_{n}^{d}\right)$ of strategies is given, the condition for deposit market equilibrium is,

$$
\sum_{j} z_{j}^{d}=\sum_{j}\left[\Phi^{s j}\left(p_{e}\right)-E^{s j}\left(p_{e}-p_{z}\right)\right] \quad \text { or } \quad \sum_{j} z_{j}^{d}=\frac{n p_{z}}{\alpha} .
$$

Summing up, the equations (11) and (12) determine the prices of fuel and deposits that clear the markets for any given profile of strategies $\left(z_{1}^{d}, \ldots, z_{n}^{d}\right)$. Formally, (11) and (12) imply price functions $P^{e}$ and $P^{z}$ such that the equilibrium prices are

$$
p_{e}=P^{e}\left(\sum_{j} z_{j}^{d}\right):=\frac{\alpha a}{\alpha+b}+\frac{\alpha a}{(\alpha+b) n} \sum_{j} z_{j}^{d} \quad \text { and } \quad p_{z}=P^{z}\left(\sum_{j} z_{j}^{d}\right):=\frac{\alpha}{n} \sum_{j} z_{j}^{d} .
$$

\subsection{Two benchmarks: Business as usual and social optimum}

Suppose now all countries seek to enhance their residents' welfare by purchasing deposits in order to curb climate damage. All countries act independently and simultaneously, and they take into account both the other countries' strategies (= deposit demands) and their own deposit demand's impact on market equilibria. Specifically, each country realizes that its deposit purchase influences the equilibrium prices (13) of fuel and deposits. By assumption, firm $i$ chooses the supply of deposits, but the (government of) country $i$ takes into account how its firm's deposit supply $z_{i}^{s}=\Phi^{s i}\left(p_{e}\right)-E^{s i}\left(p_{e}-p_{z}\right)$ from (10) changes when the equilibrium prices (13) change with variations of $z_{i}^{d}$. Country $i=1, \ldots, n$ takes $z_{j}^{d}, j \neq i$, as given and maximizes with respect to $z_{i}^{d}$

$$
\begin{aligned}
w_{i}= & B\left[E^{d i}\left(p_{e}\right)\right]+T\left[E^{s i}\left(p_{e}-p_{z}\right)\right]-p_{e}\left[E^{d i}\left(p_{e}\right)-E^{s i}\left(p_{e}-p_{z}\right)\right] \\
& -D\left[\sum_{j} \Phi^{s j}\left(p_{e}\right)-\sum_{j} z_{j}^{d}\right]-p_{z}\left[z_{i}^{d}-\Phi^{s i}\left(p_{e}\right)+E^{s i}\left(p_{e}-p_{z}\right)\right]
\end{aligned}
$$

subject to (13). In the Appendix A we determine the corresponding first-order condition, which is the same across countries, when we impose symmetry, i.e. when we set $z_{i}^{d}=z_{j}^{d}$ for all $i, j=1, \ldots, n$. In the resultant Nash equilibrium, which we refer to as business-as-usual (BAU), each country's purchase of deposits turns out to be

$$
z_{B A U}=\frac{a \delta n^{2}}{(\alpha+b)^{2}(n-1)+\alpha(\alpha+b)+\alpha \delta n^{2}} .
$$

To assess the allocative distortion in business-as-usual, observe that efficiency is char- 
acterized by the three rules ${ }^{8}$

$$
\begin{array}{ll}
\underbrace{B_{e_{i}^{d}}\left(e_{i}^{d}\right)}_{=p_{e}}=B_{e_{j}^{d}}\left(e_{j}^{d}\right) \quad i, j=1, \ldots, n, & \text { (consumption efficiency) } \\
\underbrace{K_{e_{i}^{s}}\left(e_{i}^{s}\right)}_{=p_{e}-p_{z}}=K_{e_{j}^{s}}\left(e_{j}^{s}\right) \quad i, j=1, \ldots, n, & \text { (production efficiency) } \\
n D_{e}\left(\sum_{j} e_{j}^{d}\right)=\underbrace{B_{e_{i}^{d}}\left(e_{i}^{d}\right)}_{=p_{e}}-\underbrace{K_{e_{i}^{s}}\left(e_{i}^{s}\right)}_{=p_{e}-p_{z}} i, j=1, \ldots, n . \quad \text { (damage internalization) }
\end{array}
$$

Equation (16) requires equal marginal willingness-to-pay for fuel across countries, which is satisfied according to (2). Equation (17) requires equal marginal extraction costs across countries, which is satisfied according to (9). Equation (18) requires that the marginal benefit of purchasing deposits, $n D_{e}:=\frac{\mathrm{d}(n D)}{\mathrm{d} \sum_{j} e_{j}^{d}}$, equals the marginal cost of purchasing deposits, $p_{z}$, in all countries. Interestingly, since (16) and (17) are fulfilled, the right-hand side of (18) is the same for all $i$, but the question is whether the equality sign in (18) holds. We show in the Appendix A that each country's socially optimal deposit purchase is

$$
z_{O P T}=\frac{a \delta n^{2}}{\alpha(\alpha+b)+\alpha \delta n^{2}}
$$

and hence $z_{O P T}>z_{B A U}$. Moreover, from (5) and (13) follows $\sum_{j} e_{j}^{d}=\frac{a n}{\alpha+b}-\frac{\alpha}{\alpha+b} \sum_{j} z_{j}^{d}$. Combined with (15) and (19) we get $e_{B A U}^{d}>e_{O P T}^{d}$ and $D_{e}\left(n z_{B A U}\right)>D_{e}\left(n z_{O P T}\right)$. Hence the efficiency rule (18) is violated in business-as-usual because both the marginal and the total climate damage are excessive.

\section{Coalition formation with deposit trading}

\subsection{Coalition-fringe equilibria with coalitions of given size}

Suppose now the first $m$ countries, $1 \leq m<n$, are members of a climate coalition $C:=$ $\{1,2, \ldots, m\}$ (with $C$ for coalition) and all countries in the remaining group $F:=\{m+$ $1, \ldots, n\}$ (with $F$ for fringe) are non-cooperative. Each fringe country $i \in F$ plays Nash against the coalition and against all fellow fringe countries. The coalition acts as a single player whose payoff is the aggregate welfare $\sum_{j \in C} w_{j}$ and who plays Nash against all fringe countries. Taking advantage of symmetry, we treat all countries equally within their group and therefore set $z_{i}^{d}=z_{c}$ for all $i \in C$ and $z_{i}^{d}=z_{f}$ for all $i \in F$ from the outset.

\footnotetext{
${ }^{8}$ See also Harstad (2012), equation (1).
} 
The (executive body of the) coalition takes $z_{f}$ as given and maximizes the aggregate welfare of the coalition countries,

$$
\begin{aligned}
m w_{c}= & m\left\{B\left[E^{d c}\left(p_{e}\right)\right]+T\left[E^{s c}\left(p_{e}-p_{z}\right)\right]-p_{e}\left[E^{d c}\left(p_{e}\right)-E^{s c}\left(p_{e}-p_{z}\right)\right]\right. \\
& \left.-D\left[\sum_{j} \Phi^{s j}\left(p_{e}\right)-\left(m z_{c}+(n-m) z_{f}\right)\right]-p_{z}\left[z_{c}-\Phi^{s c}\left(p_{e}\right)+E^{s c}\left(p_{e}-p_{z}\right)\right]\right\},
\end{aligned}
$$

subject to (13). ${ }^{9}$ As shown in the Appendix A, some rearrangement of the first-order condition produces a link between $z_{c}$ and $z_{f}$, denoted $z_{c}=\tilde{R}^{c}\left(z_{f}, m\right)$, such that each coalition country's best reply to predetermined $z_{f}$ is

$$
z_{c}=R^{c}\left(z_{f}, m\right):=\max \left[0, \tilde{R}^{c}\left(z_{f}, m\right)\right] .
$$

Likewise, we reconsider the first-order condition of maximizing (14) with respect to $z_{i}^{d}$ subject to (13), adapt the notation of deposit purchases appropriately, and turn the modified equation into another link between $z_{c}$ and $z_{f}$, denoted $z_{f}=\tilde{R}^{f}\left(z_{c}, m\right)$. With this information, we write each fringe country's best reply to $z_{c}$ as

$$
z_{f}=R^{f}\left(z_{c}, m\right):=\max \left[0, \tilde{R}^{f}\left(z_{c}, m\right)\right] .
$$

The Nash equilibrium, referred to as coalition-fringe equilibrium, is a strategy tuple $\left(z_{c}^{*}, z_{f}^{*}\right)$ satisfying $z_{c}^{*}=R^{c}\left(z_{f}^{*}, m\right)$ and $z_{f}^{*}=R^{f}\left(z_{c}^{*}, m\right)$. Solving (21) and (22) for $z_{c}$ and $z_{f}$ yields

$$
z_{c}^{*}=\tilde{R}^{c}(0, m)=\frac{a \delta n^{3}}{2(\alpha+b)^{2}(n-m)+\left[\alpha(\alpha+b)+\alpha \delta n^{2}\right] m}
$$

and $z_{f}^{*}=0$. That is the fringe countries find it in their self-interest not to purchase any deposits. Thus they entirely leave the burden of mitigation to the coalition. The equilibrium prices

$$
p_{e}^{*}=\frac{\alpha a}{\alpha+b}-\frac{\alpha b m}{(\alpha+b) n} z_{c}^{*}, \quad p_{z}^{*}=\frac{\alpha m}{n} z_{c}^{*} \quad \text { and } \quad p_{e}^{*}-p_{z}^{*}=\frac{\alpha a}{\alpha+b}-\frac{\alpha(\alpha+2 b) m}{(\alpha+b) n} z_{c}^{*}
$$

follow from combining (13) and (23). Since the equilibrium deposit supply is uniform across countries, (23) combined with the deposit market equilibrium specifies the equilibrium supply as $m z_{c}^{*} / n$. The main results are summarized in ${ }^{10}$

Proposition 1. For any given coalition size $m \in\{2, \ldots, n-1\}$, the coalition-fringe equilibrium is characterized as follows:

(i) The coalition buys deposits but the fringe countries do not.

\footnotetext{
${ }^{9}(13)$ is applied after replacing $\sum_{j} z_{j}^{d}$ by $m z_{c}+(n-m) z_{f}$.

${ }^{10}$ The proof of Proposition 1(ii) can be found in the Appendix A.
} 
(ii) The total amount of deposits bought is smaller and total emissions are larger than in the social optimum. The total amount of deposits bought is increasing and aggregate emissions are declining in the coalition size.

(iii) There is no trade in fuel. The coalition pays for the deposits by exporting the consumption good.

(iv) Fuel consumption and production are efficient, but global climate damage is excessive. ${ }^{11}$

(v) The fringe countries are better off than the coalition countries because their consumption of the consumption good exceeds the coalition countries' consumption of that good by the amount $p_{z}^{*} z_{c}^{*}$.

That the fringe countries refrain from buying deposits in the coalition-fringe equilibrium is a striking and unexpected result. ${ }^{12}$ If the fringe countries could, they would even respond to the coalition's equilibrium purchase $m z_{c}^{*}$ with negative deposit demand - which is economically infeasible, however. The fringe countries' reluctance to buy deposits is a strong form of free riding. The coalition presents them with an extent of climate damage reduction so large that they prefer spending their income on more consumption rather than on the purchase of deposits. It is interesting to note that in the business-as-usual scenario of Section 2 all countries do purchase deposits, although they do not cooperate. Therefore, it is not the lack of cooperation, which explains the zero deposit demand. The explanation rather is the difference in country size, recalling that the coalition is treated as a single country that is $m$ times as large as each fringe country.

According to Proposition 1(v) the fringe countries are better off than coalition countries for any given coalition size. All countries' welfare position is the same except that coalition countries buy deposits, $p_{z}^{*} z_{c}^{*}$, at the expense of the consumption good while fringe countries buy an extra amount of the consumption good for the money not spent on deposits. As we will show below the fringe countries' strong free-rider advantage does not prevent them from joining the coalition under certain conditions.

We have characterized above coalition-fringe equilibria in the parametric model as well as the allocative changes resulting from exogenous variations of the coalition size. To obtain additional results and to prepare for the analysis of coalition stability in the next section we now present a numerical illustration, called Example 1, that consists of the parameters ${ }^{13}$

\footnotetext{
${ }^{11}$ That is, (16) and (17) hold, but (18) fails to hold.

${ }^{12}$ It is unexpected because we are not aware of analyses of climate coalition formation with policy instruments other than deposit trading in which the fringe countries refrain from climate policy altogether.

${ }^{13}$ The parameter $\bar{r}$, the endowment of the productive factor, needs not be specified here, because it enters the outcomes in an additive way and thus leaves the results undistorted.
} 
$\alpha=110, a=100, b=100^{2}, \delta=1$ and $n=100$. The focus of Example 1 is on (exogenous) variations of the coalition size. Although coalition sizes are integers, it is convenient to consider equilibrium values as functions whose domain is the interval $[0, n]$. Formally, we introduce the notation

$$
\begin{aligned}
& e_{c}^{s *}=e_{c}^{d *}=e_{f}^{s *}=e_{f}^{d *}=\mathcal{E}(m), \quad p_{e}^{*}=\mathcal{P}^{e}(m), \quad p_{z}^{*}=\mathcal{P}^{z}(m), \quad w_{c}^{*}=\mathcal{W}^{c}(m), \\
& w_{f}^{*}=\mathcal{W}^{f}(m), \quad z_{c}^{*}=\mathcal{Z}^{c}(m) \quad \text { and } \quad z_{c}^{s *}=z_{f}^{s *}=\mathcal{Z}^{s}(m) .
\end{aligned}
$$
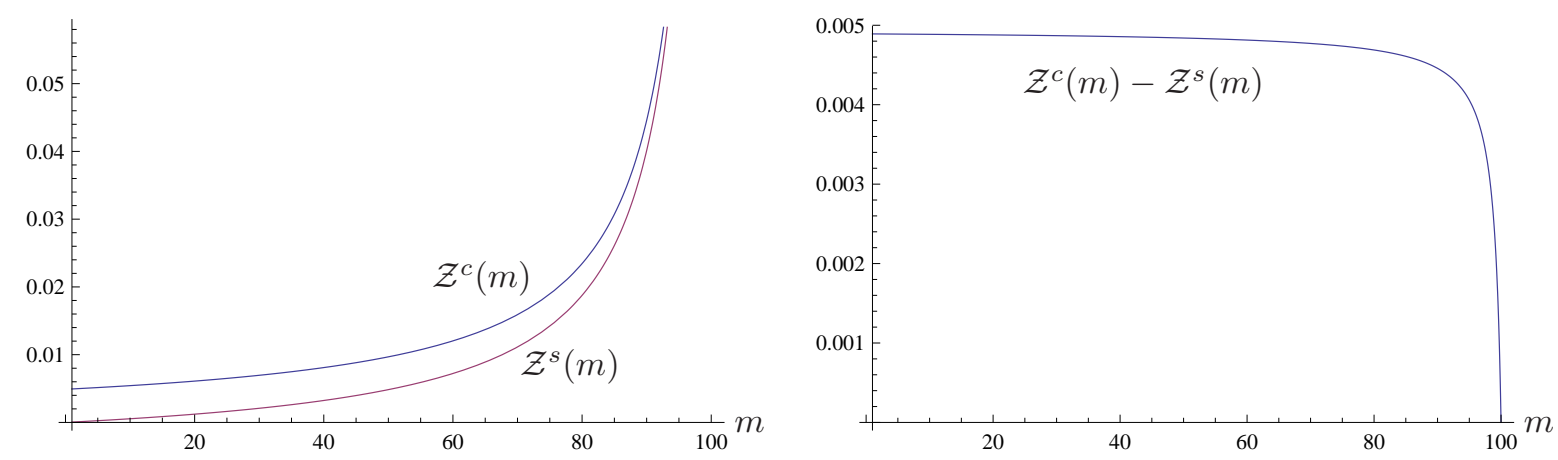

Figure 1: Deposit purchase and the coalition's deposit imports (Example 1)

According to the left panel of Figure 1 each country's deposit sales $\mathcal{Z}^{s}(m)$ and each coalition country's deposit purchases $\mathcal{Z}^{c}(m)$ are progressively increasing in the coalition size, and for any given $m$ the coalition country's purchase $\mathcal{Z}^{c}(m)$ exceeds its sale. That is necessary for equilibrium on the deposit market because the fringe countries do not buy deposits. In fact, the vertical distance between $\mathcal{Z}^{c}(m)$ and $\mathcal{Z}^{s}(m)$, that is $\mathcal{Z}^{c}(m)-\mathcal{Z}^{s}(m)=$ $\frac{n-m}{m} \mathcal{Z}^{s}(m)$, constitutes the coalition countries' imports of deposits paid for by exports of the consumption good. As the right panel of Figure 1 shows, these imports decrease in $m$. They decrease only slightly when $m$ is small and medium, but they rapidly approach zero when $m$ is large and approaches $n$.
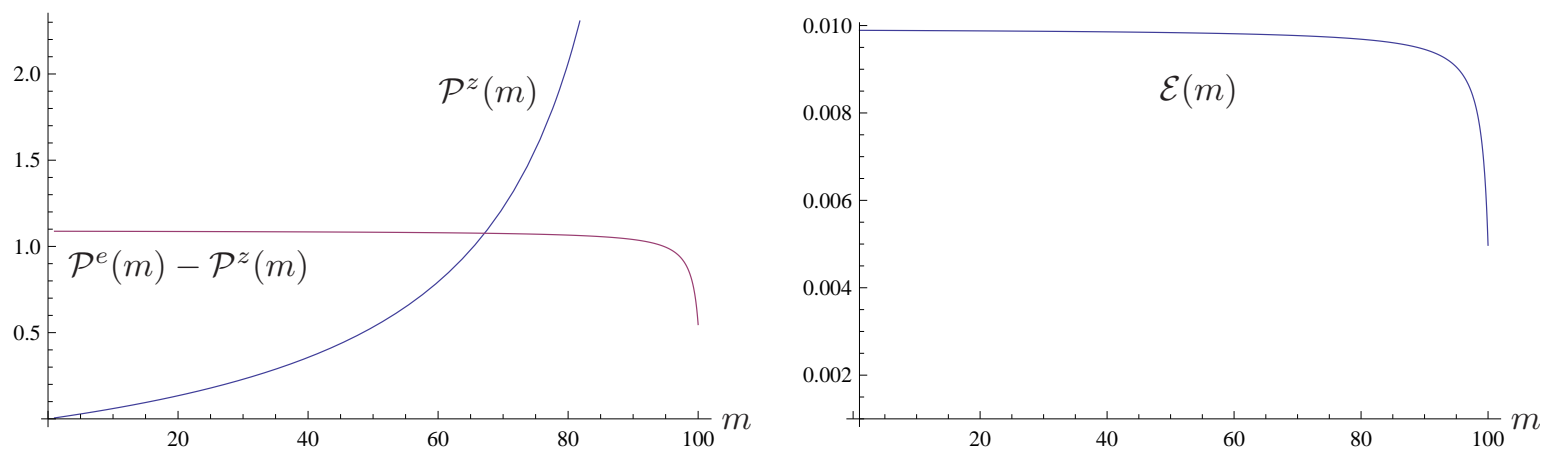

Figure 2: Fuel consumption and the prices for fuel and deposits (Example 1) 
According to the left panel of Figure 2 the deposit price is progressively increasing in $m$ while the producer price of fuel, $p_{e}^{*}-p_{z}^{*}$, decreases when $m$ gets larger. Since (9) holds for all countries, each country's fuel production and consumption must be decreasing in $m$, which is shown in the right panel of Figure 2. As an implication, the climate damage $D[n \mathcal{E}(m)]$ is also strictly declining in $m$.
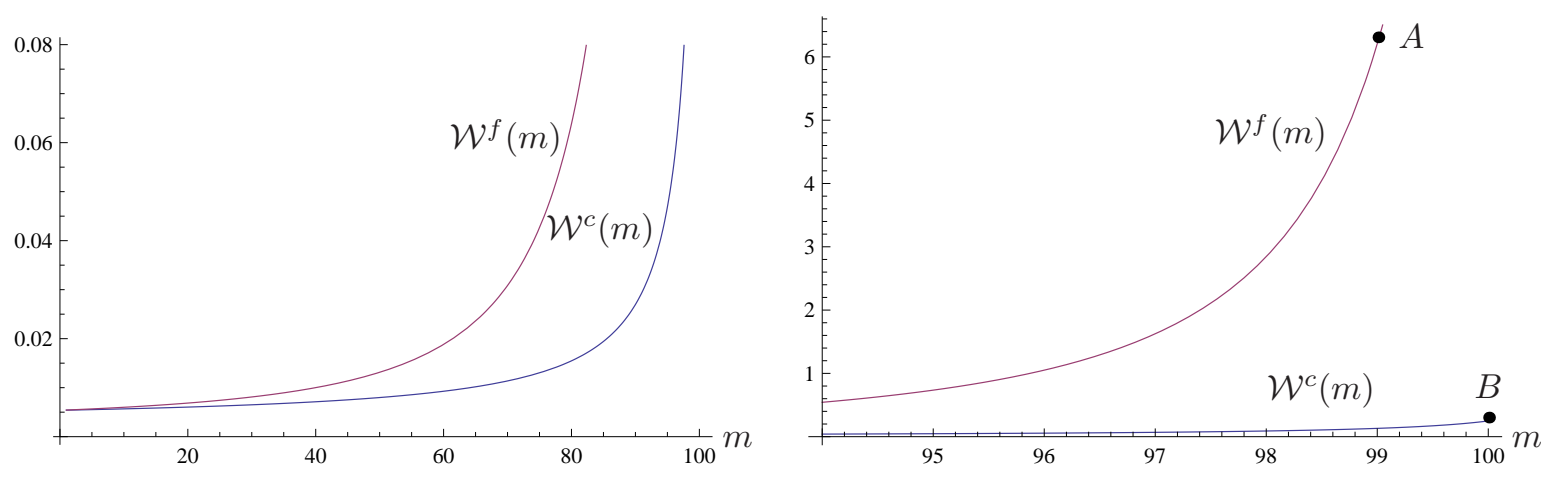

Figure 3: Welfare of coalition and fringe countries (Example 1)

In the left panel of Figure 3 the graph of each country's welfare $\mathcal{W}^{v}(m), v=c, f$, is progressively increasing in the coalition size $m$ and for any given $m$ fringe countries are better off than coalition countries. The welfare difference is $\mathcal{W}^{f}(m)-\mathcal{W}^{c}(m)=\mathcal{P}^{z}(m) \mathcal{Z}^{c}(m)=$ $\alpha \mathcal{Z}^{c}(m)^{2}$. The right panel of Figure 3 is an enlarged segment of the graphs of the welfare functions $\mathcal{W}^{f}$ and $\mathcal{W}^{c}$ for high values of $m .{ }^{14}$ We will come back to that panel when we discuss the issue of coalition stability below.

\subsection{Stability of climate coalitions}

In the preceding Section 3.1 we have presupposed the existence of climate coalitions of alternative sizes, and our focus has been on characterizing the coalition-fringe equilibrium and its change following exogenous variations of the coalition size. Now we turn to the issue of coalition stability. Since supranational authorities for the effective enforcement of IEAs are not available, such agreements will not be concluded unless they are self-enforcing in the sense that no coalition country has an incentive to defect and no fringe country has an incentive to join the climate agreement. In formal language, an IEA with $m \in\{2, \ldots, n\}$ signatories is said to be self-enforcing - or equivalently, a coalition of size $m$ is said to be

\footnotetext{
${ }^{14}$ The only reason why the shapes of the graphs in the left and the right panel of Figure 3 differ significantly, are the different scales on the vertical and horizontal axes of both panels.
} 
stable - if it satisfies the conditions ${ }^{15}$

$$
\mathcal{W}^{c}(m)-\mathcal{W}^{f}(m-1) \geq 0 \text { and } \quad \mathcal{W}^{f}(m)-\mathcal{W}^{c}(m+1) \geq 0,
$$

known as the condition of internal and external stability, respectively. Our subsequent stability analysis focuses on the (in)stability of the grand coalition. First, we show that the grand coalition is unstable in the Example 1 introduced above. Then we show that a sufficiently large increase of the parameter $b$ in the otherwise unchanged Example 1 renders the grand coalition stable. Next we characterize the parameter subspace in which the grand coalition is stable (Proposition 2) and finally provide insight in the (non-)existence of subglobal stable coalitions (Proposition 3).

Necessary and sufficient for the stability of the grand coalition is the condition for the internal stability, $\mathcal{W}^{c}(n)-\mathcal{W}^{f}(n-1) \geq 0$. Whether that condition holds in Example 1 can be conveniently examined in the right panel of Figure 3 . In that figure, the point $A$ represents $\mathcal{W}^{f}(99)$ and the point $B$ represents $\mathcal{W}^{c}(100)$. From $\mathcal{W}^{c}(100)<\mathcal{W}^{f}(99)$ follows that the grand coalition is not stable in Example 1. Next we change the parameter $b$ in Example 1 from $b=100^{2}$ to $b=575,000$ and denote the resultant parameters as Example 2 . Figure 4 contains the graphs of the welfare functions $\mathcal{W}^{c}$ and $\mathcal{W}^{f}$ of Example 2. When we check the stability of the grand coalition in Figure 4 (proceeding as in Figure 3) we readily get $\mathcal{W}^{c}(100)-\mathcal{W}^{f}(99)=1.1759 \cdot 10^{-7}$. The comparison of the Figures 3 and 4 shows that the shapes of the welfare curves are very similar. In both cases the coalition countries' welfare rises when moving from $m=n-1$ to $m=n$. However, the increase $\mathcal{W}^{c}(100)-\mathcal{W}^{f}(99)$ is rather small in Example 1, but larger in Example 2.
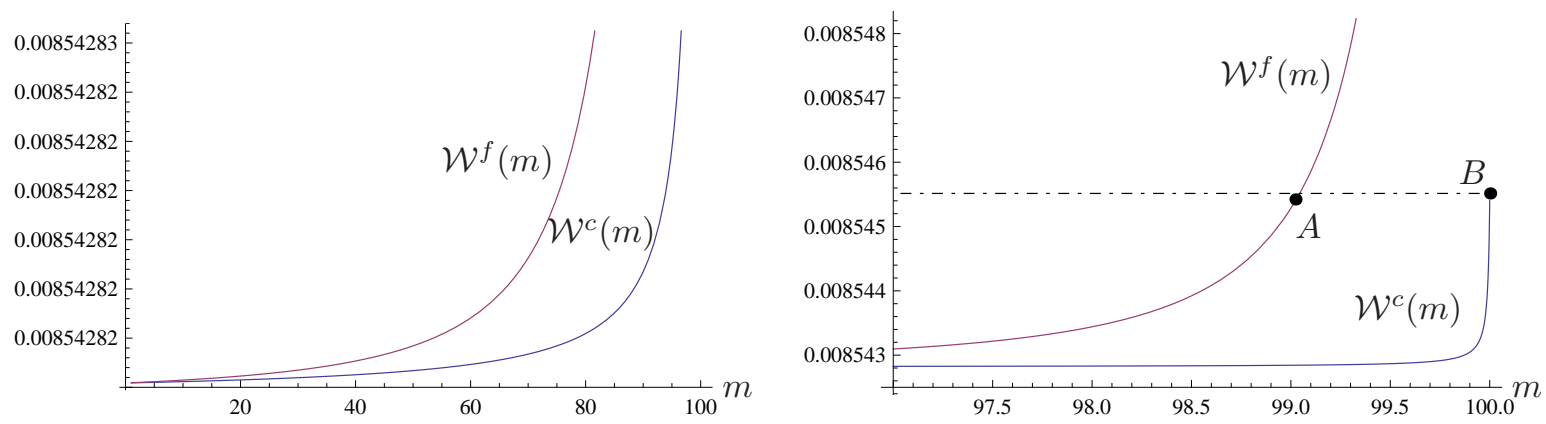

Figure 4: Welfare of coalition and fringe countries (Example 2)

Since the only difference in the specification of the Examples 1 and 2 is the size of the parameter $b$, it clearly is that difference which causes the difference in their stability pattern.

\footnotetext{
${ }^{15}$ This concept of self-enforcement or coalition stability was originally introduced by D'Aspremont et al. (1983) in the context of cartel formation and was first applied to the formation of IEAs by Hoel (1992), Carraro and Siniscalco (1993) and Barrett (1994).
} 
Economically, an increase of the parameter $b$ amounts to an inward shift of all fuel demand curves. ${ }^{16}$ That shift reduces fuel consumption and hence climate damage. In other words, the Examples 1 and 2 suggest that the grand coalition is the more likely stable, the lower the demand - i.e. the preference and willingness-to-pay - for fuel.

The striking finding that the grand coalition may be stable calls for analyzing the determinants of stability in more detail. In fact, it is possible to specify completely the parameter subset in which the grand coalition is stable.

\section{Proposition 2 .}

(i) In the space of feasible parameters ${ }^{17}$ the grand coalition is stable, if and only if

$$
F(\alpha, b, \delta, n):=2 b^{2}-\alpha b\left(n^{2}-2 n-3\right)-\alpha^{2}\left(n^{2}-2 n-1\right)-\alpha \delta(n-1)^{2} n^{2}>0 .
$$

(ii) Ceteris paribus, the grand coalition is the more likely stable,

- the lower the fuel extraction costs $\left(F_{\alpha}<0\right)$;

- the lower the demand for fuel $\left(F_{b}>0\right.$, if $\left.b>\alpha\left(n^{2}-2 n-3\right) / 4\right)$;

- the less severe the climate damage $\left(F_{\delta}<0\right)$;

- the smaller the total number of countries $\left(F_{n}<0\right)$.

Proposition 2 is a strong result because the inequality (26) is a necessary and sufficient condition for the stability of the grand coalition. (26) allows exploring the role of parameters for the (in)stability of the grand coalition. To develop an intuition for the impact of parameter variations on stability, observe that increasing fuel demand $(b \downarrow)$ and increasing climate damage per unit of emissions $(\delta \uparrow$ or $n \uparrow$ ) tend to destabilize a stable (grand) coalition, ceteris paribus, because these parametric shifts directly or indirectly increase total climate damage. The impact of the fuel-demand parameter $b$ has already been clarified above in the transition from Example 1 to Example 2: Lower values of $b$ increase the demand for fuel, increase emissions and climate damage and thus tend to destabilize the grand coalition according to (26). Total climate damage, i.e. the climate damage summed over all countries, is increasing in the parameters $n$ and $\delta$. Since $F(\alpha, b, \delta, n)$ decreases in $n$ and $\delta$, successively increasing values of $n$ and $\delta$ eventually render the grand coalition unstable. Thus, with regard to the parameters $b, \delta$ and $n$ the thrust of Proposition 2 is that the grand coalition is stable if total climate damage produced by these parameters is not too severe.

\footnotetext{
${ }^{16}$ More precisely, the shift takes the form of a rotation of all countries' demand curves towards the origin around the invariant choke price $p_{e}=a$.

${ }^{17}$ The crucial feasibility constraint is the non-negativity of fuel demands. We have carefully observed that constraint in our numerical simulations.
} 
To improve further our understanding of the role of the parameter $b$ for the stability of the grand coalition, suppose the coalition of size $m=n-1$ prevails and consider the only fringe country's cost and benefit of joining the coalition. Its benefit of joining consists of the climate damage reduction, formally captured by ${ }^{18} \mathcal{D}(n-1)-\mathcal{D}(n)$. Its cost of joining the grand coalition consists of consumption welfare foregone, formally reflected by $\mathcal{K}^{f}(n-1)-\mathcal{K}^{c}(n)$, where $\mathcal{K}^{f}(n-1)$ is the only fringe country's consumption welfare defined as the welfare derived from its consumption of fuel and the consumption good. These costs and benefits are plotted in Figure 5 for variations of $b$. For small values of $b$ the fringe country suffers from massive losses of consumption welfare, while the benefit from climate damage reduction is small. Increasing $b$ slightly reduces the climate damage and thus diminishes the benefit of joining the coalition. However, increasing $b$ also reduces the loss of consumption welfare but much more than the benefit. As a consequence, there exists a positive value of $b$, say $\tilde{b}$ in the right panel of Figure 5 , at which cost and benefit curves intersect such that the grand coalition is stable if and only if $b \geq \tilde{b}$.
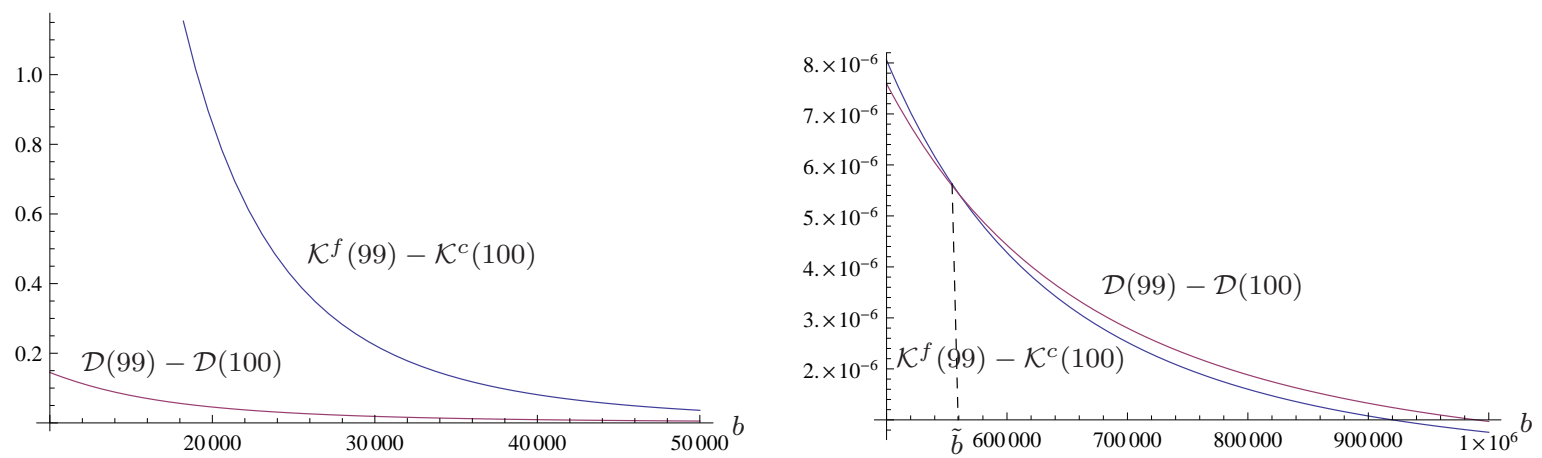

Figure 5: The last fringe country's benefit and cost of joining the given coalition of size $m=n-1=99$ depending on the size of the parameter $b$
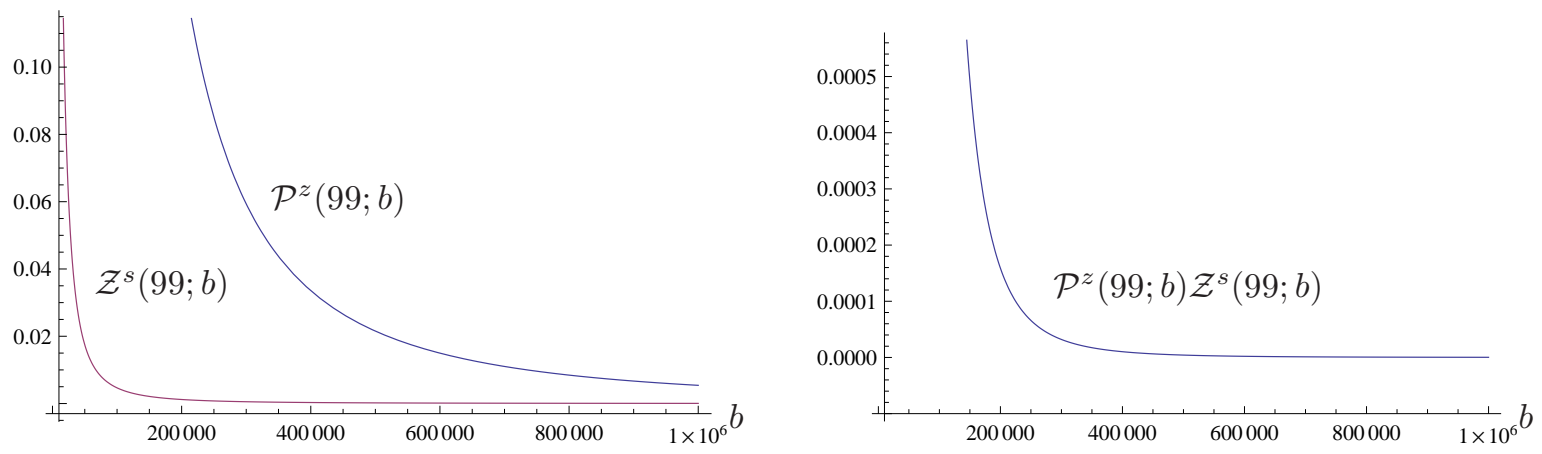

Figure 6: Deposit price, deposit supply and the fringe country's deposit export for a given coalition of size $m=n-1=99$ depending on the size of the parameter $b$

\footnotetext{
${ }^{18}$ Observe that $\mathcal{D}(m)=D\left(m e_{c}^{d *}+(n-m) e_{f}^{d *}\right), \mathcal{K}^{c}(m)=B\left(e_{c}^{d *}\right)+x_{c}^{d *}$ and $\mathcal{K}^{f}(m)=B\left(e_{f}^{d *}\right)+x_{f}^{d *}$.
} 
The reason for the massive losses of consumption welfare for small values of $b$ lies in the coalition's purchase of deposits shown in the right panel of Figure 6. Recall that among the countries in the grand coalition there is no trade of deposits. In contrast, in case of a coalition of size $n-1$ the fringe country's (consumption) welfare is larger than the coalition country's (consumption) welfare due to the revenues from selling deposits. If the fuel demand is high (low $b$ ), the coalition seeks to avoid high climate damage by purchasing many deposits at a high price as shown in the left panel of Figure 6. Hence for small values of $b$ large damages are tantamount to a large deposit income of fringe countries' that renders the grand coalition unstable.

The effect of variations in the parameter $\alpha$ is puzzling. Smaller values of $\alpha$ imply lower fuel extraction costs. The dependence of the only fringe country's cost and benefit of joining the grand coalition on $\alpha$ is illustrated in Figure 7. While the fringe country's benefit is slightly decreasing in $\alpha$, the cost is first strongly increasing and then decreasing in $\alpha$. Figure 7 reveals that the cost and benefit curves intersect at some point $\tilde{\alpha}$ implying that the grand coalition is [un]stable for all $\alpha<[>] \tilde{\alpha}$. Observe that the less expensive fuel extraction the more fuel is consumed, the higher are emissions and the higher is the climate damage. As a consequence for small values of $\alpha$ the coalition purchases many deposits (see the right panel of Figure 8). One might expect that the coalition's expenditures on deposits are high, but due to very low deposit prices the expenditures are low as shown in the left panel of Figure 8. The fringe country's low income from selling deposits reduces its consumption welfare only slightly for small values of $\alpha$, as shown in the left panel of Figure 8, which in turn ensures the stability of the grand coalition.
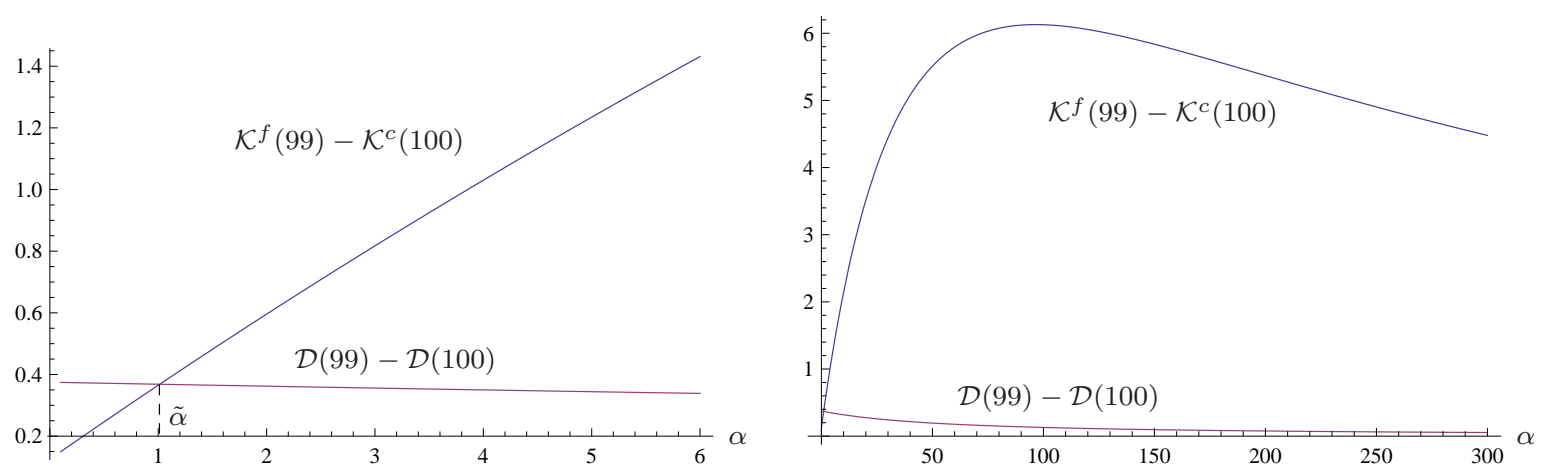

Figure 7: The only fringe country's benefit and cost of joining the coalition of size $m=$ $n-1=99$ depending on the size of the parameter $\alpha$ 

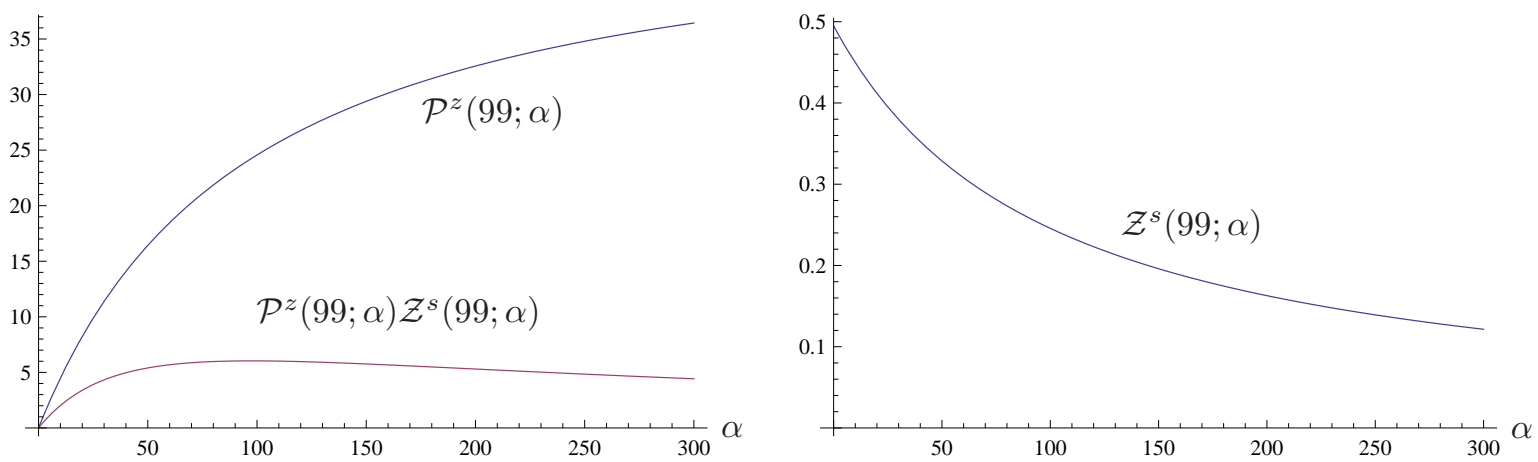

Figure 8: Deposit price and the fringe country's deposit export for a given coalition of size $m=n-1=99$ depending on the size of the parameter $\alpha$

We have extensively focused on the conditions under which the grand coalition is stable, because an all encompassing international climate agreement is of utmost interest. As indicated above, we now briefly turn to the question whether there are also stable coalitions that do not encompass all countries. The answer is given in ${ }^{19}$

Proposition 3. $\quad$ Suppose that $n \geq 4$.

(i) Either no coalition is stable

(ii) or the grand coalition (of size $m=n$ ) is the only stable coalition.

Finally, we turn to the potential gains of cooperation. There is a folk theorem of the international environmental agreement literature stating that "... the equilibrium size of a stable IEA is small except when the potential gains from cooperation are also small" (Karp and Simon, 2012). ${ }^{20}$ An indicator for the potential gains from cooperation is the relative welfare gap $\frac{w_{O P T}-w_{B A U}}{w_{O P T}} \cdot 100$ that measures the relative welfare gain of moving from BAU to the social optimum. The left panel of Figure 9 shows the relative welfare gap for variations of the parameter $b$. The welfare gap is decreasing in $b$ and the grand coalition is stable for $b>\tilde{b}$. Hence the smaller the gains from cooperation the more likely it is that the grand coalition is stable. We conclude that the relation between the size of the parameter $b$ and the stability of the grand coalition is in line with the folk theorem mentioned above. Turning to extraction costs, we observe that the relative welfare gap is decreasing in $\alpha$ as illustrated in the right panel of Figure 9, but that the coalition is stable for $\alpha<\tilde{\alpha}$. Hence the relation between the size of the parameter $\alpha$ and the stability of the grand coalition is at variance with the folk theorem according to which large (and effective) coalitions are unstable, unless the potential gains from cooperation are small.

\footnotetext{
${ }^{19}$ The proof of Proposition 3 is given in the Appendix A.

${ }^{20}$ See also Barrett (2003).
} 

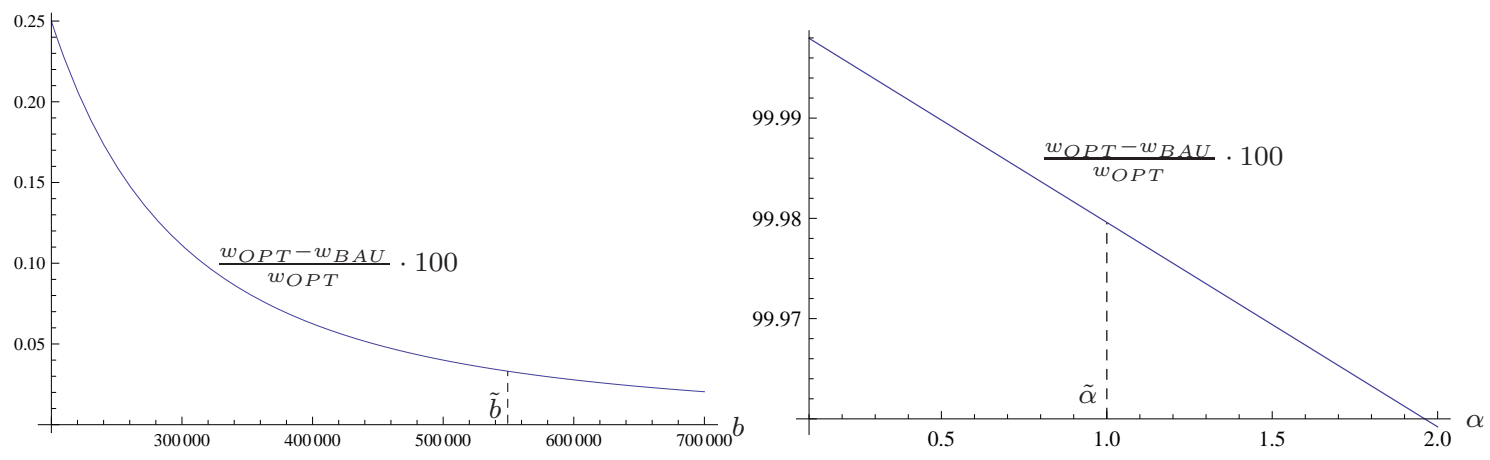

Figure 9: The welfare gap in Example 1 depending on the size of the parameters $b(\tilde{b}=$ $548,766)$ and $\alpha(\tilde{\alpha}=1.02)$

\section{Coalition formation with deposit trading and deposit supply regulation}

In the previous Section 3, the only climate policy instrument at the governments' disposal was the purchase of deposits. Our assumption was that the extraction firms own all domestic deposits and are free to sell (the right to extract) them. In practice, many governments probably would not leave deposit sales at the domestic extraction firms' discretion because reserves of natural resources and fossil energy are of eminent national interest. We therefore extend the analysis of the last section by providing the governments with the option to tax or subsidize the supply of domestic deposits. Suppose, the price at which country $i$ 's extraction firm can sell deposits is $p_{z}+\sigma_{i}$, which means that if $\sigma_{i}>0\left[\sigma_{i}<0\right]$, deposit sales are subsidized [taxed]. ${ }^{21}$ We will refer to $\sigma_{i}$ as a (deposit supply) subsidy if its sign is unspecified keeping in mind that we deal with a (deposit supply) tax, if $\sigma_{i}<0$. The important feature of the extended model is that all governments now act strategically with respect to two policy parameters, the deposit purchase $z_{i}^{d}$, as before, and the subsidy rate $\sigma_{i}$.

The modifications of the formal model required by the introduction of the subsidy are straightforward and therefore delegated to the Appendix B. Instead of discussing here the details of introducing the subsidy on equilibrium prices and values in Example 1 as in Section 3 , we turn directly to the welfare changes and the stability conditions of the grand coalition. ${ }^{22}$

\footnotetext{
${ }^{21}$ Government $i$ may induce its extraction firm to supply more $\left(\sigma_{i}>0\right)$ or less $\left(\sigma_{i}<0\right)$ deposits than in the absence of subsidization. If it should not want to sell domestic deposits at all, it simply sets $\sigma_{i}=-p_{z}$.

${ }^{22}$ The interested reader is referred to the Appendix B for a detailed discussion of Example 1 with subsidies.
} 
In Figure 10, solid [dashed] curves relate to the model with [without] subsidies and the superscript $\sigma$ indicates the welfare in the model with subsidies for Example 2. According to the left panel of Figure 10, for any given coalition size $m \in[2, n-1]$ both fringe countries and coalition countries improve their welfare in the coalition-fringe equilibrium when using the subsidy. Since the welfare of the grand coalition is independent of the regimes with and without subsidies, the welfare $\operatorname{loss} \mathcal{W}^{f}(n-1)-\mathcal{W}^{c}(n)$ increases in the scenario with subsidy. That is shown for Example 2 in the right panel of Figure 10. The consequence for the stability of the grand coalition is surprising. While in Example 2 the grand coalition is stable in the regime without subsidies, the subsidy increases the fringe country's welfare from point $A$ to point $C$ and thus raises it above the welfare of a coalition country in the grand coalition that is given by the point $B\left(\mathcal{W}^{c \sigma}(100)-\mathcal{W}^{f \sigma}(99)=-1.428 \cdot 10^{-7}\right)$ in Figure 10. We conclude that introducing the subsidy makes free-riding more attractive and makes the instability of the grand coalition more likely.
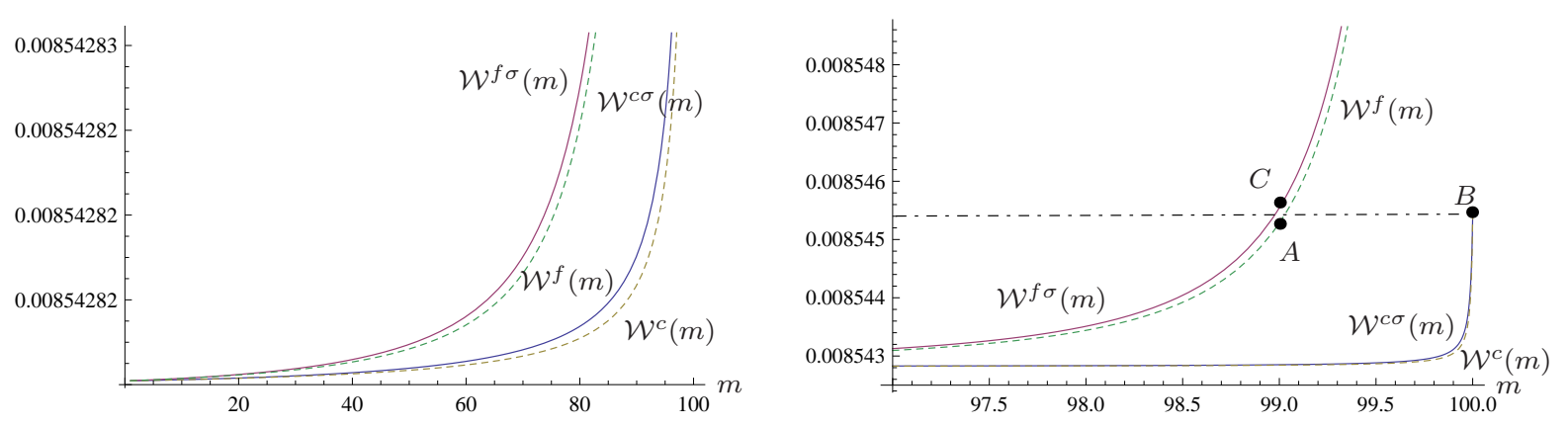

Figure 10: Welfare of the fringe country and the coalition (Example 2)

As in Section 3.2, it is desirable to gain more general information on the determinants of the stability of grand coalitions in the regime with subsidies. A systematic analysis delegated to the Appendix $\mathrm{C}$ yields

\section{Proposition 4.}

(i) In the space of feasible parameters the grand coalition with deposit trading and deposit subsidies is stable, if and only if

$$
\begin{aligned}
F^{\sigma}(\alpha, b, \delta, n) & :=b^{2}(3 n-2)^{2}-\alpha b\left(5 n^{4}-18 n^{3}+6 n^{2}+10 n-5\right) \\
& -\alpha^{2}\left(5 n^{4}-18 n^{3}+15 n^{2}-2 n-1\right)-\alpha \delta(n-1)^{3} n^{2}(5 n-3)>0 .
\end{aligned}
$$

(ii) Ceteris paribus, the grand coalition is the more likely stable,

- the lower the fuel extraction costs $\left(F_{\alpha}^{\sigma}<0\right)$; 
- the lower the demand for fuel $\left(F_{b}^{\sigma}>0\right.$, if $b>\alpha\left(5 n^{4}-18 n^{3}+6 n^{2}+10 n-5\right) /[2(3 n-$ $\left.2)^{2}\right]$;

- the less severe the climate damage $\left(F_{\delta}^{\sigma}<0\right)$;

- the smaller the total number of countries $\left(F_{n}^{\sigma}<0\right)$.

The comparison of the Propositions 2 and 4 suggests that the role of parameters for securing stable grand coalitions is similar with and without subsidies. The note-worthy differences between both regimes that generalize our findings in Example 2 are presented in

Proposition 5. For $n \geq 4$ the set of parameters with stable grand coalitions is smaller in case of deposit policies with deposit-supply subsidies than without. If there is a stable grand coalition in case of subsidies, it is also stable in the absence of subsidies. The reverse statement does not hold.

\section{Concluding remarks}

We analyzed the formation of self-enforcing climate agreements, or stable climate coalitions, when all countries have the option to fight climate change by purchasing (the right to extract) fossil-energy deposits, and we also allowed for combining that policy with taxes or subsidies on the supply of deposits. We found that all coalition countries buy deposits but the noncooperative countries do not. In the policy regime without taxes/subsidies, we provided necessary and sufficient conditions for the stability of the grand coalition. The additional availability of the tax/subsidy instrument improves the countries' welfare, but renders less favorable the conditions for stable grand and sub-global coalitions. The deposit purchase policy turns out to be appealing with regard to its favorable conditions for stable (grand) coalitions.

Two caveats need to be reemphasized, however. First, it is not clear how robust our results - and those of earlier pertaining literature - are because tractability requires imposing restrictive assumption. Second, it is unclear how severe the difficulties are to fight climate change with such supply-side policies in practice, especially when one accounts for the important role of time which we disregarded in the present paper. In our view, further thorough theoretical and applied analyses of such policies are warranted, since the search for effective means to fight climate change is urgent and since the present paper suggests that the incentives to form self-enforcing IEAs of supply-side climate policies are promising. 


\section{References}

Barrett, S. (2003): Environment and Statecraft. Oxford University Press, Oxford UK.

Barrett, S. (1994): Self-enforcing international environmental agreements. Oxford Economic Papers 46, 878-894.

Bohm, P. (1993): Incomplete international cooperation to reduce $\mathrm{CO}_{2}$ emissions: alternative policies. Journal of Environmental Economics and Management 24, 258-71.

Carraro, C. and D. Siniscalco (1993): Strategies for the international protection of the environment. Journal of Public Economics 52, 309-328.

D'Aspremont, C., Jacquemin, A, Gabszewicz, J.J. and J.A. Weymark (1983): On the stability of collusive price leadership. Canadian Journal of Economics 16, 17-25.

Diamantoudi, E. and E. Sartzetakis (2006): Stable international environmental agreements: An analytical approach. Journal of Public Economic Theory 8, 247-263.

Eichner, T. and R. Pethig (2013): Self-enforcing-environmental agreements and international trade. Journal of Public Economics 102, 37-50.

Eichner, T. and R. Pethig (2015): Self-enforcing international environmental agreements and trade: taxes versus caps, Oxford Economic Papers, forthcoming.

Finus, M. and P. Pintassilgo (2013): The role of uncertainty and learning for the success of international climate agreements. Journal of Public Economics 103, 29-43.

Harstad, B. (2012): Buy coal! A case for supply-side environmental policy. Journal of Political Economy 120, 77-115.

Harstad, B. (2010): Buy coal? Deposit markets prevent carbon leakage, NBER working paper No. 16119.

Hoel, M. (1992): International environmental conventions: the case of uniform reductions of emissions. Environmental and Resource Economics 2, 141-159.

Hoel, M. and K. Schneider (1997): Incentives to participate in an international environmental agreement. Environmental and Resource Economics 9, 153-170.

Karp, L. and L. Simon (2013): Participation games and international environmental agreements: A non-parametric model. Journal of Environmental Economics and Management 65, 326-344.

Rubio, S.J. and A. Ulph (2006): Self-enforcing agreements and international trade in greenhouse emission rights. Oxford Economic Papers 58, 233-263. 


\section{Appendix}

\section{Appendix A}

\section{Derivation of (15):}

The first-order condition of maximizing (14) is given by

$$
\begin{aligned}
\frac{\mathrm{d} w_{i}}{\mathrm{~d} z_{i}^{d}}= & D_{e}-p_{z}-\left(z_{i}^{d}-z_{i}^{s}\right) P_{z_{i}^{d}}^{z}-\left[D_{e} \sum_{j} \Phi_{p_{e}}^{s j}+e_{i}^{d}-e_{i}^{s}-p_{z} \Phi_{p_{e}}^{s i}\right] P_{z_{i}^{d}}^{e} \\
= & \delta \cdot\left(\frac{n P^{e}}{\alpha}-\sum_{j} z_{j}^{d}\right)-P^{z}-(z_{i}^{d}-\underbrace{\frac{P^{z}}{\alpha}}_{=z_{i}^{s}}) \frac{\alpha}{n} \\
& -[\delta \cdot\left(\frac{n P^{e}}{\alpha}-\sum_{j} z_{j}^{d}\right) \frac{n}{\alpha}+\underbrace{\frac{a-P^{e}}{b}-\frac{P^{e}-P^{z}}{\alpha}}_{e_{i}^{d}-e_{i}^{s}}-\frac{P^{z}}{\alpha}] \frac{\alpha b}{n(\alpha+b)}=0 .
\end{aligned}
$$

In a symmetric Nash equilibrium the equalities $z_{i}^{s}=z_{i}^{d}$ and $e_{i}^{s}=e_{i}^{d}$ hold and (A1) simplifies to

$$
\frac{\mathrm{d} w_{i}}{\mathrm{~d} z_{i}^{d}}=\delta \cdot\left(\frac{n P^{e}}{\alpha}-\sum_{j} z_{j}^{d}\right)-P^{z}-\left[\delta \cdot\left(\frac{n P^{e}}{\alpha}-\sum_{j} z_{j}^{d}\right) \frac{n}{\alpha}-\frac{P^{z}}{\alpha}\right] \frac{\alpha b}{n(\alpha+b)}=0 .
$$

Inserting the price functions $P^{e}$ and $P^{z}$ from (13) and setting $\sum_{j} z_{j}^{d}=n z_{B A U}$, we solve (A2) for $z_{B A U}$ and obtain (15). We insert (15) in $P^{e}$ and $P^{z}$ and plug the outcome into the welfare function (14) to get

$$
w_{B A U}=\frac{a^{2}[b(n-1)+\alpha n]\left[b^{2}(n-1)+\alpha n(\alpha-(n-2) n \delta)+b\left(\alpha(2 n-1)-(n-1) n^{2} \delta\right)\right]}{2\left[b^{2}(n-1)+\alpha b(2 n-1)+\alpha n(\alpha+n \delta)\right]^{2}}(
$$

\section{Derivation of (19):}

Maximizing aggregate welfare

$$
\begin{aligned}
n w_{i}= & n B\left[E^{d i}\left(p_{e}\right)\right]+T\left[E^{s i}\left(p_{e}-p_{z}\right)\right]-p_{e} \underbrace{\sum_{j}\left(e_{j}^{d}-e_{j}^{s}\right)}_{=0} \\
-D & {\left[\sum_{j} \Phi^{s j}\left(p_{e}\right)-\sum_{j} z_{j}^{d}\right]-p_{z} \underbrace{\sum_{j}\left(z_{j}^{d}-z_{j}^{s}\right)}_{=0} }
\end{aligned}
$$


subject to (13) yields

$$
\begin{aligned}
\frac{\mathrm{d}\left(n w_{i}\right)}{\mathrm{d} \sum_{j} z_{j}^{d}} & =n B_{e_{i}^{d}} E_{p_{e}}^{d i} P_{\sum_{j} z_{j}^{d}}^{e}-n K_{e_{i}^{s}} E_{\left(p_{e}-p_{z}\right)}^{s i}\left(P_{\sum_{j} z_{j}^{d}}^{e}-P_{\sum_{j} z_{j}^{d}}^{z}\right)-n D_{e}\left(n \Phi_{p_{e}}^{s i} P_{\sum_{j} z_{j}^{d}}^{e}-1\right) \\
& =-\underbrace{B_{e_{i}^{d}}}_{=p_{e}} \frac{\alpha}{\alpha+b}+\underbrace{K_{e_{i}^{s}}}_{=p_{e}-p_{z}} \frac{\alpha}{\alpha+b}+n D_{e} \frac{\alpha}{\alpha+b} \\
& =\frac{\alpha}{\alpha+b}\left[n \delta\left(\frac{n P^{e}}{\alpha}-\sum_{j} z_{j}^{d}\right)-P^{z}\right]=0 .
\end{aligned}
$$

Accounting for $P^{e}$ and $P^{z}$ from (13), for $\sum_{j} z_{j}^{d}=n z_{O P T}$ in (A5), and solving (A5) for $z_{O P T}$ establishes (19).

\section{Derivation of the coalition-fringe equilibrium:}

The coalition maximizes (20) subject to

$$
P^{e}\left(z_{c}, z_{f}\right)=\frac{\alpha a}{\alpha+b}+\frac{\alpha b\left[m z_{c}+(n-m) z_{f}\right]}{(\alpha+b) n}, \quad P^{z}\left(z_{c}, z_{f}\right)=\frac{\alpha\left[m z_{c}+(n-m) z_{f}\right]}{n} .
$$

The first-order condition is given by

$$
\begin{aligned}
\frac{\mathrm{d}\left(m w_{c}\right)}{\mathrm{d} z_{c}}= & m\left\{D_{e}-p_{z}-\left(z_{c}-z_{c}^{s}\right) P_{z_{c}}^{z}-\left[D_{e} \sum_{j} \Phi_{p_{e}}^{s j}+e_{i}^{d}-e_{i}^{s}-p_{z} \Phi_{p_{e}}^{s c}\right] P_{z_{c}}^{e}\right\} \\
& m\left\{m \delta \cdot\left[\frac{n P^{e}}{\alpha}-\left(m z_{c}+(n-m) z_{f}\right)\right]-P^{z}-\left(z_{c}-\frac{P^{z}}{\alpha}\right) \frac{\alpha m}{n}\right. \\
& \left.-\left[\delta \cdot\left(\frac{n P^{e}}{\alpha}-\left(m z_{c}+(n-m) z_{f}\right)\right) \frac{n}{\alpha}+\frac{a-P^{e}}{b}-\frac{P^{e}}{\alpha}\right] \frac{m \alpha b}{n(\alpha+b)}\right\}=0 .(
\end{aligned}
$$

Inserting the price functions (A6) and rearranging (A7) yields

$$
a \delta m n^{3}-(\alpha+b)^{2} m n z_{c}-\theta_{c}\left[m z_{c}+(n-m) z_{f}\right]=0
$$

where $\theta_{c}:=(\alpha+b)^{2}(n-m)-(\alpha+b) b m+\alpha \delta m n^{2}$. Solving (A8) for $z_{c}$ results in the coalition country's reaction function

$$
z_{c}=\tilde{R}^{c}\left(z_{f}, m\right):=\frac{a \delta n^{3}}{\theta_{c}+(\alpha+b)^{2} n}-\frac{\theta_{c}}{\theta_{c}+(\alpha+b)^{2} n} \cdot \frac{n-m}{m} z_{f} .
$$

Making use of $\sum_{j} z_{j}^{d}=m z_{c}+(n-m) z_{f}$ and of $P^{e}$ and $P^{z}$ from (A6) in the fringe country's first-order condition (A2), we obtain, after rearrangement of terms,

$$
a \delta n^{3}-(\alpha+b)^{2} n z_{f}-\theta_{f}\left[m z_{c}+(n-m) z_{f}\right]=0,
$$

where $\theta_{f}:=(\alpha+b)^{2}(n-1)-(\alpha+b) b+\alpha \delta n^{2}$. Solving (A10) for $z_{f}$ results in the fringe country's reaction function

$$
z_{f}=\tilde{R}^{f}\left(z_{c}, m\right):=\frac{a \delta n^{3}}{\theta_{f}(n-m)+(\alpha+b)^{2} n}-\frac{\theta_{f} m}{\theta_{f}(n-m)+(\alpha+b)^{2} n} z_{c} .
$$


The solution of (A9) and (A11) is

$$
\begin{aligned}
& \tilde{z}_{f}=\frac{(2-m) n^{3} \alpha \delta}{\theta_{c}+\theta_{f}(n-m)+(\alpha+b)^{2} n}, \\
& \tilde{z}_{c}=\frac{[(n-m)(m-1)+m] n^{3} \alpha \delta}{\theta_{c}+\theta_{f}(n-m)+(\alpha+b)^{2} n}>0 .
\end{aligned}
$$

We find that $\tilde{z}_{f} \leqq 0 \quad \Longleftrightarrow m \geqq 2$. Owing to the constraint $z_{c}, z_{f} \geq 0$ the tuple $\left(\tilde{z}_{c}, \tilde{z}_{f}\right)$ is a Nash equilibrium if and only if $m=2$ (which is an unimportant case).

Under the constraint $z_{c}, z_{f} \geq 0$ the fringe countries' reaction function is

$$
z_{f}=\left[0, \tilde{R}^{f}\left(z_{c}, m\right)\right]
$$

Since $z_{f}=0$ in the relevant domain of $z_{c}$, we safely assume that the fringe countries set $z_{f}=0$ as a response to any given $z_{c} \geq 0$. Thus we readily infer from (A9) that the Nash equilibrium $\left(z_{c}^{*}, z_{f}^{*}\right)$ is given by $z_{f}^{*}=0$ and

$$
z_{c}^{*}=\tilde{R}^{c}(0, m)=\frac{a \delta n^{3}}{\theta_{c}+(\alpha+b)^{2} n}
$$

which yields (23) after some further rearrangement of terms.

\section{Proof of Proposition 1(ii):}

Straightforward calculations yield:

$$
\begin{aligned}
m z_{c}^{*}-n z_{o p t} & =-\frac{2 a(\alpha+b)^{2}(n-m) n^{3} \delta}{\alpha\left(\alpha+b+n^{2} \delta\right) N}<0, \\
\frac{\partial\left(m z_{c}^{*}\right)}{\partial m} & =\frac{2 a(b+c)^{2} n^{4} \delta}{N^{2}}>0, \\
m e_{c}^{d *}+(n-m) e_{f}^{d *}-n e_{O P T} & =\frac{2 a(\alpha+b)(n-m) n^{3} \delta}{\left(\alpha+b+n^{2} \delta\right) N}>0, \\
\frac{\partial\left[m e_{c}^{d *}+(n-m) e_{f}^{d *}\right]}{\partial m} & =\frac{2 a c(\alpha+b) n^{4} \delta}{N^{2}}>0 .
\end{aligned}
$$

where $N:=2(\alpha+b)^{2}(n-m)+\left[\alpha(\alpha+b)+\alpha \delta n^{2}\right] m>0$. 


\section{Proof of Proposition 2:}

Inserting the equilibrium deposit demand, deposit supply, fuel demand and fuel supply into the welfare function yields

$$
\begin{aligned}
\mathcal{W}^{c}(m) & =\frac{a^{2}\left[\alpha(2 n-m)+2 b(n-m)-2(n-m) n^{2} \delta\right]}{2 N}+\bar{r} \quad \text { for } 2 \leq m \leq n, \\
\mathcal{W}^{f}(m) & =\frac{a^{2}\left\{4 b^{3}(n-m)^{2}+\alpha b\left[\alpha\left(12 n^{2}-16 m n+5 m^{2}\right)-8(n-m)^{2} n^{2} \delta\right]\right.}{4 N^{2}} \\
& +\frac{4 b^{2}(n-m)\left[\alpha(3 n-2 m)-(n-m) n^{2} \delta\right]+\alpha^{3}(2 n-m)^{2}}{4 N^{2}} \\
& +\frac{\left.\alpha^{2}\left(8 m n-4 n^{2}-3 m^{2}\right) n^{2} \delta+2 m^{2} n^{4} \alpha \delta^{2}\right\}}{4 N^{2}}+\bar{r} \quad \text { for } 2 \leq m \leq n-1 .
\end{aligned}
$$

The grand coalition is stable, iff $\mathcal{W}^{c}(n)-\mathcal{W}^{f}(n-1)>0$ which is equivalent to (26). Differentiation of $F(\alpha, b, \delta, n)$ with respect to $\alpha, b, \delta$ and $n$, respectively, yields

$$
\begin{aligned}
& F_{\alpha}=-2 \alpha\left(n^{2}-2 n-1\right)-b\left(n^{2}-2 n-3\right)-(n-1)^{2} n^{2} \delta<0, \\
& F_{b}=4 b-\alpha\left(n^{2}-2 n-3\right), \\
& F_{\delta}=-\alpha(n-1)^{2} n^{2}<0, \\
& F_{n}=-2 \alpha(n-1)[\alpha+b+(2 n-1) n \delta]<0 .
\end{aligned}
$$

\section{Proof of Proposition 3:}

Suppose that $3 \leq m \leq n-1$. Then $\mathcal{W}^{c}(m)-\mathcal{W}^{f}(m-1) \gtreqless 0$ iff

$$
\begin{aligned}
G(m)= & 2 b^{2}\left[-m(n+2)+2 n+m^{2}+1\right]-\alpha b\left[m(4 n+6)-8 n-3 m^{2}-3\right] \\
& -\alpha^{2}\left[2 m(n+1)-4 n-m^{2}-1\right]-\alpha \delta(m-1)^{2} n^{2} \gtreqless 0 .
\end{aligned}
$$

Observe that

$$
\begin{aligned}
G(3) & =-2\left[b^{2}(n-4)+2 b \alpha(n-3)+\alpha^{2}(n-2)+2 \alpha n^{2} \delta\right]<0 \\
G(n-1) & =-2 b^{2}(n-4)-\alpha b\left(n^{2}-12\right)-\alpha^{2}\left(n^{2}-2 n-4\right)-\alpha \delta(n-2)^{2} n^{2}<0 .
\end{aligned}
$$

From (A17) and (A18) we get

$$
G(3)-G(n-1)=(n-4) \alpha n\left(\alpha+b+n^{2} \delta\right)>0 .
$$

Differentiation of $G$ leads to

$$
\begin{aligned}
G_{m} & =2\left[b^{2}(2 m-2-n)+\alpha b(3 m-3-2 n)+\alpha^{2}(m-1-n)-\alpha(m-1) n^{2} \delta\right] \\
& =2\left[\left[2 b^{2}+3 \alpha b+\alpha\left(\alpha-n^{2} \delta\right)\right](m-1)-b^{2} n-2 \alpha b n-\alpha^{2} n\right] \\
& =2\left[2 b^{2}+3 \alpha b+\alpha\left(\alpha-n^{2} \delta\right)\right](m-1)-2(\alpha+b)^{2} n, \\
G_{m m} & =2\left[2 b^{2}+3 \alpha b+\alpha\left(\alpha-n^{2} \delta\right)\right] .
\end{aligned}
$$


Suppose first that $\left[2 b^{2}+3 \alpha b+\alpha\left(\alpha-n^{2} \delta\right)\right]>0$ and hence $G_{m m}>0$. Combined with $G(3)<0$ and $G(n-1)<0$ from (A17) and (A18), respectively, $G_{m m}>0$ establishes $G(m)<0$ for all $m \in[3, n-1]$. Next, consider $\left[2 b^{2}+3 \alpha b+\alpha\left(\alpha-n^{2} \delta\right)\right]<0$. In that case $G_{m}<0$ and $G_{m m}<0$ holds. Due to $G(3)>G(n-1)$ from (A19) we get $G(m)<0$ for all $m \in[3, n-1]$.

Finally, we consider the external stability condition for a coalition of size $m=2$. Straightforward calculations lead to

$$
\begin{gathered}
\mathcal{W}^{c}(2)-\mathcal{W}^{f}(1)=\mathcal{W}^{c}(2)-w_{B A U} \\
=-\frac{a^{2} \alpha n^{4} \delta^{2}\left[b^{2}\left(n^{2}-4 n-3\right)+\alpha b\left(2 n^{2}-7 n+4\right)+\alpha^{2}\left(n^{2}-3 n+1\right)+\alpha \delta(n-2) n^{2}\right]}{2\left[b^{2}(n-1)+\alpha b(2 n-1)+\alpha n(\alpha+n \delta)\right]^{2}\left[b^{2}(n-2)+\alpha b(2 n-3)+\alpha^{2}(n-1)+\alpha \delta n^{2}\right]}<0 .
\end{gathered}
$$

To sum up, we have proven that all coalitionS of size $m \in[2, n-1]$ are unstable.

\section{Proof of Proposition 5:}

From the definition of $F, F^{\sigma}$ in (26) and (27), respectively, we infer

$$
\begin{aligned}
& F \gtreqless 0 \Longleftrightarrow \delta \gtreqless \frac{2 b^{2}-\alpha b\left(n^{2}-2 n-3\right)-\alpha^{2}\left(n^{2}-2 n-1\right)}{\alpha(n-1)^{2} n^{2}}=: \hat{\delta} \\
& F^{\sigma} \gtreqless 0 \Longleftrightarrow 0 \\
& \delta \gtreqless \frac{b^{2}(3 n-2)^{2}-\alpha b\left(5 n^{4}-18 n^{3}+6 n^{2}+10 n-5\right)-\alpha^{2}\left(5 n^{4}-18 n^{3}+15 n^{2}-2 n-1\right)}{\alpha(n-1)^{3} n^{2}(5 n-3)}=: \hat{\delta}^{\sigma} .
\end{aligned}
$$

Observe that $\hat{\delta}-\hat{\delta}^{\sigma}=\frac{(\alpha+b)^{2}\left(n^{2}-4 n+2\right)}{\alpha(n-1)^{3} n^{2}(5 n-3)}>0$. Next, we insert $\hat{\delta}$ from (A23) into $F^{\sigma}$ from (27) to get

$$
F^{\sigma}(\alpha, k, \hat{\delta}, n)=-(\alpha+b)^{2}\left(n^{2}-4 n+2\right)<0 .
$$

Recall that $F_{\delta}<0, F_{\delta}^{\sigma}<0$.

(i) Suppose that $\delta>\hat{\delta}$. Then the grand coalition is unstable with and without subsidies.

(ii) Suppose that $\delta<\hat{\delta}^{\sigma}$. Then the grand coalition is stable with and without subsidies.

(iii) Suppose that $\hat{\delta}^{\sigma}<\delta<\hat{\delta}$. Then the grand coalition is stable in case without subsidies, but unstable in case with subsidies.

\section{Appendix B: Extension: Deposit supply regulation (only for the referees)}

The modifications of the formal model required by the introduction of the subsidy are straightforward and therefore delegated to the Appendix C. In the business-as-usual scenario, all countries turn out to refrain from subsidizing the supply of deposits $\left(\sigma_{i}=0\right.$ for all $\left.i\right)$ due 
to symmetry such that the business-as-usual allocation is the same as in the case of deposit purchases without subsidies. Following the procedure in Section 3, we will now characterize the coalition-fringe equilibria for alternatively given coalition sizes and then turn to the welfare functions which are needed for the stability analysis. In order to clarify the impact of deposit-supply subsidies on results we will compare the outcome with and without the subsidy.

\section{Coalition-fringe equilibria with given coalition size}

We denote by $z_{c}$ and $z_{f}$ the demand for deposits of coalition and fringe countries, as before, and by $\sigma_{c}$ and $\sigma_{f}$ the corresponding subsidy rates. The Appendix $\mathrm{C}$ proves $^{23}$

Proposition 6. For any given coalition size $m \in\{2, \ldots, n-1\}$, the coalition-fringe equilibrium with deposit trading and deposit-supply subsidies is characterized as follows:

(i) As in Proposition 1, the coalition buys deposits but fringe countries do not.

(ii) The coalition subsidizes deposit sales $\left(\sigma_{c}>0\right)$ and fringe countries tax them $\left(\sigma_{f}<0\right)$. In absolute terms, the subsidy rate $\sigma_{c}$ is $(n-1)$ times as high as the tax rate $\sigma_{f}$.

(iii) The total amount of deposits bought is smaller than in the social optimum but larger than in the absence of subsidies. Total emissions are larger than in the social optimum but smaller than in the absence of subsidies.

(iv) The coalition imports deposits, as in Proposition 1, but in contrast to Proposition 1 it also imports fuel and pays for all imports by exporting the consumption good.

(v) Fuel consumption is efficient and global climate damage is excessive, as in Proposition 1, but production is not efficient anymore.

The next step is to illustrate the key results of Proposition 6 by means of Example 1 from Section 3. That illustration provides additional information about the dependence of equilibrium prices and quantities on coalition sizes. The subsequent numerical analysis also aims to improve the understanding of how the subsidy changes the allocation in coalitionfringe equilibria, i.e. of how the allocations differ if governments subsidize or do not subsidize the supply of deposits. In all figures below, solid [dashed] curves relate to the model with [without] subsidies and variables and functional signs with [without] superscript $\sigma$ indicate equilibrium values in the model with [without] subsidies.

\footnotetext{
${ }^{23}$ To avoid clutter we omit the asterix for equilibrium values when there is no risk of confusion.
} 

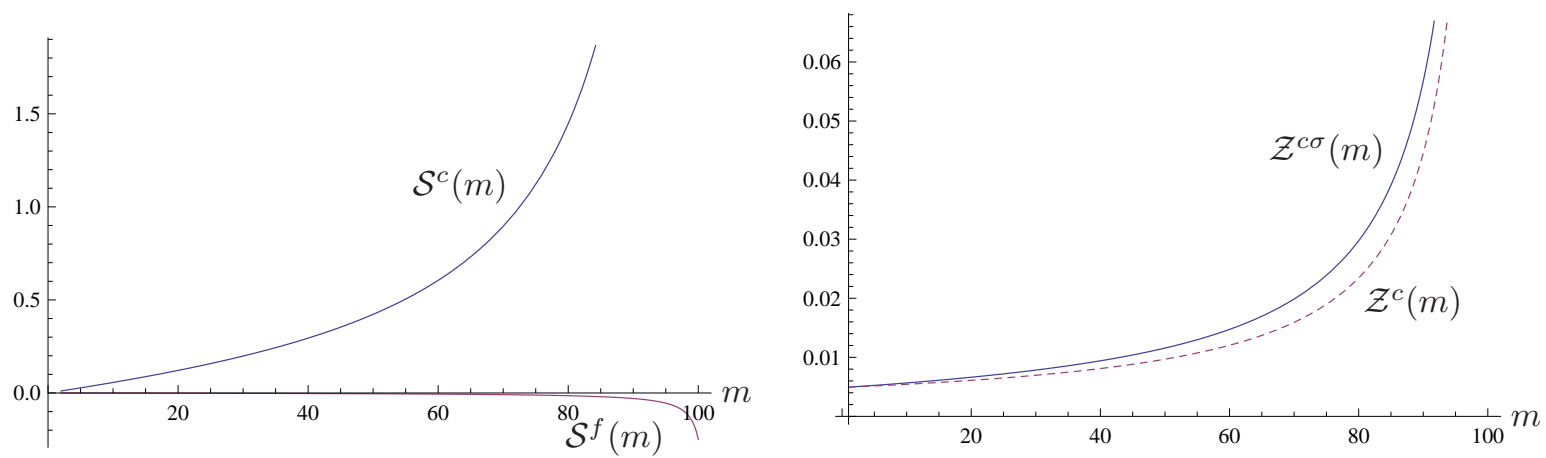

Figure 11: Deposit-supply subsidy and deposit purchases (Example 1)

$$
\left(\sigma_{c}=\mathcal{S}^{c}(m) ; \sigma_{f}=\mathcal{S}^{f}(m) ; z_{c}=\mathcal{Z}^{c}(m) ; z_{c}^{\sigma}=\mathcal{Z}^{c \sigma}(m)\right)
$$

Figure 11 illustrates the inequalities $z_{c}^{\sigma}>z_{c}$ and $\sigma_{c}>-(n-1) \sigma_{f}$ and shows that the coalition countries' deposit purchases and the subsidy rates (in absolute terms) are progressively rising in the coalition size. Larger coalitions subsidize more heavily and buy larger quantities of deposits; fringe countries respond to the coalition's climate policy and its stringency almost as in the case without deposit-supply regulation.

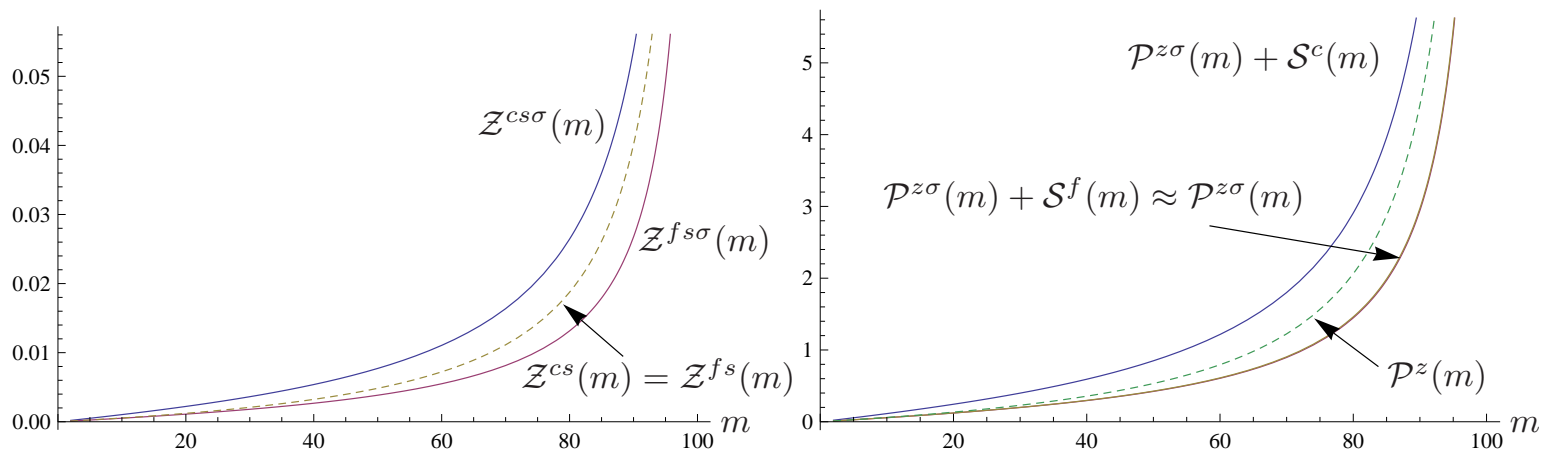

Figure 12: Deposit supply and producer prices of deposits (Example 1)

$$
\left(p_{c}=\mathcal{P}^{c}(m) ; p_{z}^{\sigma}=\mathcal{P}^{z \sigma}(m) ; z_{v}^{s}=\mathcal{Z}^{v s}(m) ; z_{v}^{s \sigma}=\mathcal{Z}^{v s \sigma}(m) ; v=c, f\right)
$$

Figure 12 describes the supply side of the deposit market. In the left panel, the ranking of quantities is $z_{c}^{s \sigma}>z^{s}>z_{f}^{s \sigma}$ for all $m$, and all quantities increase in $m$ progressively. It is immediately clear from the right panel of Figure 12 that the changes of deposit supplies in the left panel are induced by the patterns and changes of producer prices of deposits, $p_{z}^{\sigma}+\sigma_{c}>p_{z}>p_{z}^{\sigma}+\sigma_{f}$ (where $\left|\sigma_{f}\right|$ is so small that $\left.p_{z}^{\sigma}+\sigma_{f} \approx p_{z}^{\sigma}\right)$.

The Figures 13 and 14 illustrate equilibrium quantities and prices on the fuel market. According to Figure 14 the fuel demand curves $\mathcal{E}^{d}(m)$ and $\mathcal{E}^{d \sigma}(m)$ are declining in $m$. They 


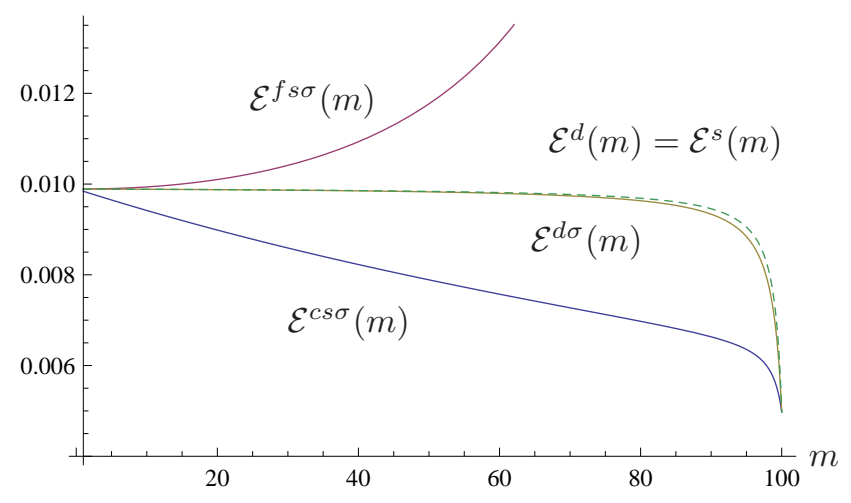

Figure 13: Demand for and supply of fuel (Example 1)

$$
\left(e_{c}^{d}=e_{f}^{d}=e^{d}=\mathcal{E}^{d}(m) ; e_{c}^{d \sigma}=e_{f}^{d \sigma}=e^{d \sigma}=\mathcal{E}^{d \sigma}(m) ; e_{v}^{s \sigma}=\mathcal{E}^{v s \sigma}(m) ; v=c, f\right)
$$
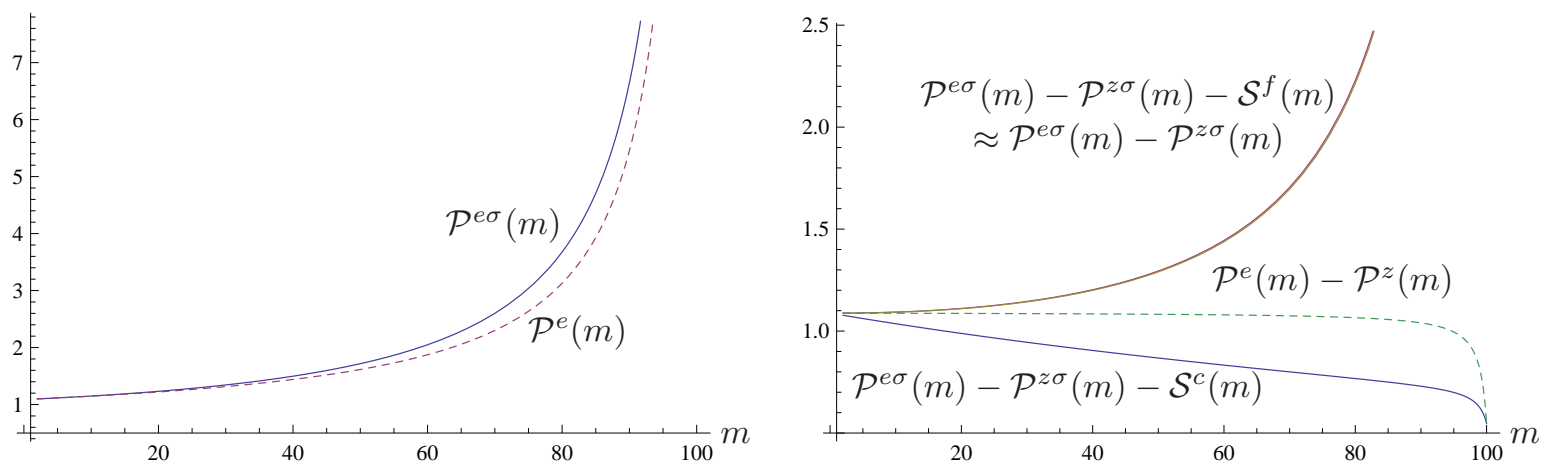

Figure 14: Consumer and producer prices of fuel (Example 1)

$$
\left(p_{e}=\mathcal{P}^{e}(m) ; p_{e}^{\sigma}=\mathcal{P}^{e \sigma}(m)\right)
$$

differ only slightly because the price difference $p_{e}^{\sigma}-p_{e}$ in Figure 14 is small. In contrast, in Figure 13 the subsidies/taxes drive a large wedge between the fuel supply of fringe and coalition countries, $e_{f}^{s \sigma}>e^{s}=e^{d}>e_{c}^{s \sigma}$. Analogous to the case of the deposit market, the reason for that wedge are changes in the producer price of fuel, which are closely linked to changes in deposit prices. The right panel of Figure 14 shows that with increasing $m$, fringe [coalition] countries face increasing [decreasing] producer prices of fuel and hence increase [reduce] their fuel supply, $p_{e}^{\sigma}-p_{z}^{\sigma}-\sigma_{f} \uparrow \Rightarrow e_{f}^{s \sigma} \uparrow\left[p_{e}^{\sigma}-p_{z}^{\sigma}-\sigma_{c} \downarrow \Rightarrow e_{c}^{s \sigma} \downarrow\right]$.

According to Figure 15, the coalition's quantitative imports of deposits and fuel are increasing in $m$, when $m$ is small and medium-sized. The imports attain a maximum, when coalitions are rather large, and they sharply decline when $m$ approaches $n .{ }^{24}$ The imports eventually decline, because a growing number of coalition countries buy deposits from a shrinking number of fringe countries. Figure 15 also shows that the coalition's strategic use of the subsidy results in a significant reduction of its quantitative deposit imports. Since

\footnotetext{
${ }^{24}$ Recall that fuel is not traded in the absence of subsidies.
} 

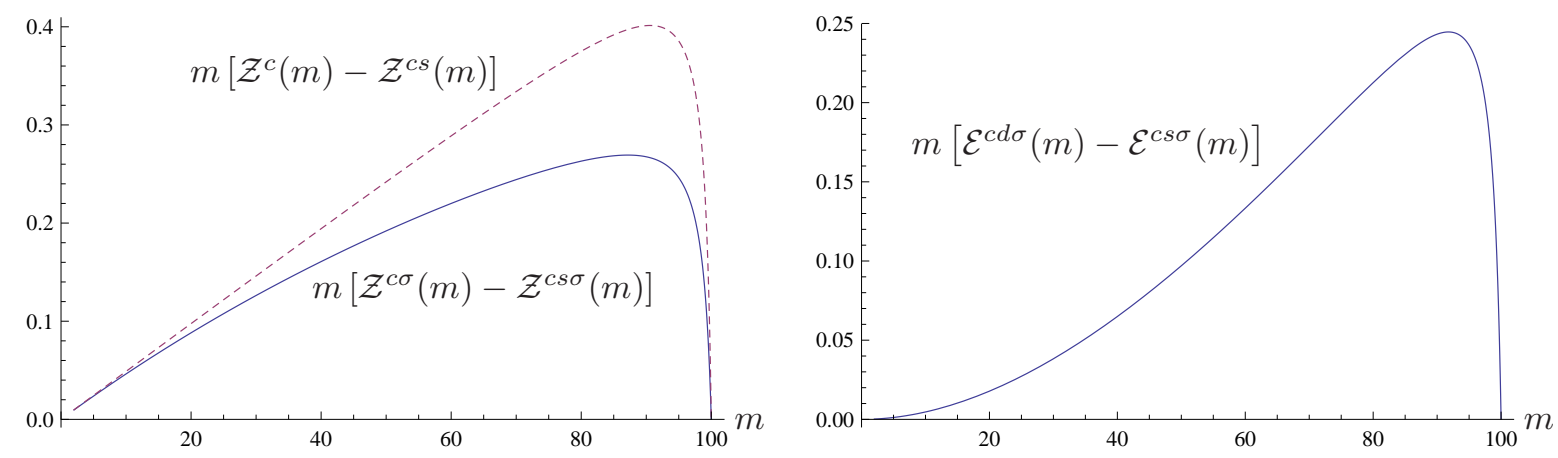

Figure 15: The coalition's imports of deposits and fuel (Example 1)

$p_{z}^{\sigma}<p_{z}$, the value of deposit imports shrinks even more than the quantity. The money saved on deposit imports is spent on consumption.
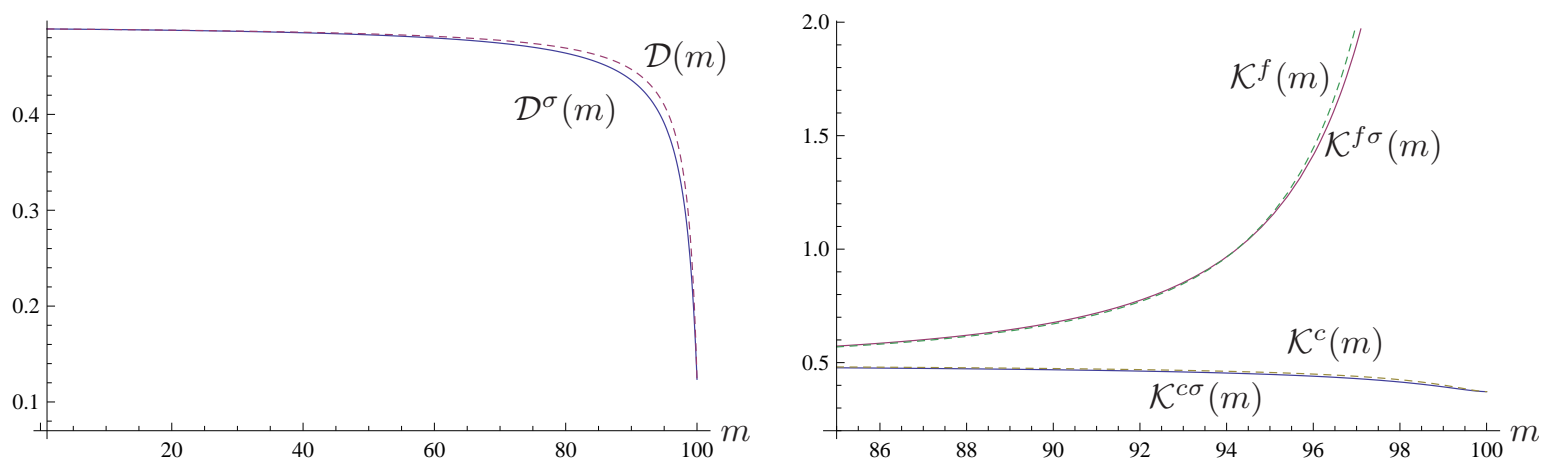

Figure 16: Climate damage and consumption welfare (Example 1)

$$
\begin{gathered}
\left(\mathcal{D}(m):=\frac{\delta}{2}\left[\mathcal{E}^{d}(m)\right]^{2}, \mathcal{D}^{\sigma}(m):=\frac{\delta}{2}\left[\mathcal{E}^{d \sigma}(m)\right]^{2}\right. \\
\left.\mathcal{K}^{v}(m):=B\left[\mathcal{E}^{d}(m)\right]+\mathcal{X}^{d v}(m), \mathcal{K}^{v \sigma}(m):=B\left[\mathcal{E}^{d \sigma}(m)\right]+\mathcal{X}^{d v \sigma}(m) ; v=c, f\right)
\end{gathered}
$$

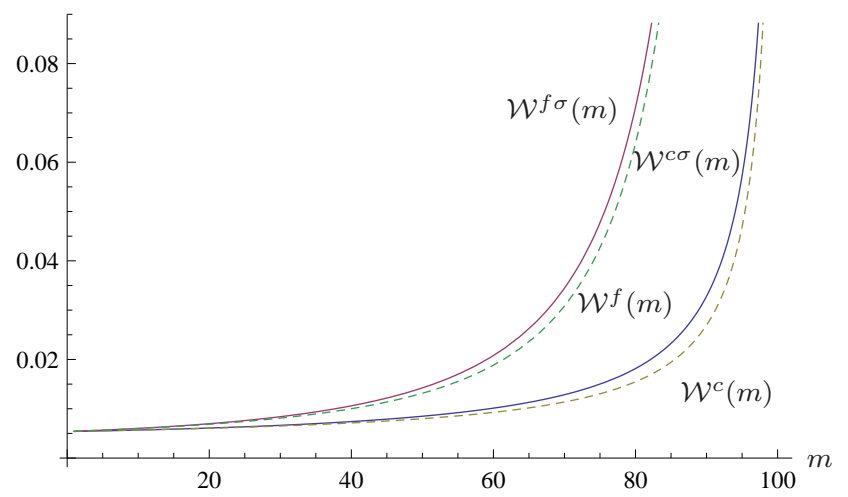

Figure 17: Welfare (Example 1)

The Figures 16 and 17 describe the dependence of the countries' welfare on coalition size and compare the regimes with and without subsidy. As the left panel of Figure 16 shows, 
the use of subsidies reduces the climate damage. The damage declines in $m$ slightly only, when the coalition is small and medium-sized and declines steeply, when $m$ approaches $n$. The right panel of Figure 16 shows how the consumption welfare, i.e. the welfare consumers derive from consuming fuel and the consumption good, depends on $m$. For large $m$, the use of subsidies slightly reduces both the coalition countries' and the fringe countries' consumption welfare. The 'partial welfares' of Figure 16 add up to the total welfare of coalition and fringe countries in Figure 17. According to that figure, the loss of consumption welfare countries incur upon use of the subsidy is overcompensated by the reduced climate damage such that with the subsidy both the coalition and fringe countries enhance their own overall welfare.

\section{Appendix C: Derivations relating to the deposit supply regulation (only for the referees)}

\section{Derivation of the equilibrium prices:}

Utility maximization and profit maximization yields

$$
\begin{aligned}
e_{i}^{d}= & E^{d i}\left(p_{e}\right)=\frac{a-p_{e}}{b}, \\
& \mathcal{E}^{s i}\left(p_{e}\right)=\frac{p_{e}}{\alpha} \\
e_{i}^{s}= & E^{s i}\left(p_{e}-p_{z}\right)=\frac{p_{e}-p_{z}-a \sigma_{i}}{\alpha}, \\
z_{i}^{s}= & \frac{p_{z}+\sigma_{i}}{\alpha} .
\end{aligned}
$$

The deposit market is in equilibrium, if

$$
\sum_{j} z_{j}^{d}=\sum_{j} z_{j}^{s} \Longleftrightarrow p_{z}=\frac{\alpha}{n} \sum_{j} z_{j}^{d}-\frac{\sum_{j} \sigma_{j}}{n}=: P^{z}\left(z_{1}^{d}, \ldots, z_{n}^{d}, \sigma_{1}, \ldots, \sigma_{n}\right),
$$

and the fuel market is in equilibrium, if

$$
\sum_{j} e_{j}^{d}=\sum_{j} e_{j}^{s} \quad \Longleftrightarrow \quad p_{e}=\frac{\alpha a}{\alpha+b}+\frac{\alpha b}{(\alpha+b) n} \sum_{j} z_{j}^{d}=: P^{e}\left(z_{1}^{d}, \ldots, z_{n}^{d}\right) .
$$

\section{BAU:}

Each country maximizes with respect to $z_{i}^{d}$ and $\sigma_{i}$ the welfare

$$
\begin{aligned}
w_{i}= & U^{i}\left[E^{d i}\left(p_{e}\right)\right]+T^{i}\left[E^{s i}\left(p_{e}-p_{z}-\sigma_{i}\right)\right]-p_{e}\left[E^{d i}\left(p_{e}\right)-E^{s i}\left(p_{e}-p_{z}-\sigma_{i}\right)\right] \\
& -D\left[\sum_{j} \Phi^{s j}\left(p_{e}\right)-\sum_{j} z_{j}^{d}\right]-p_{z}\left[z_{i}^{d}-\Phi^{s i}\left(p_{e}\right)+E^{s i}\left(p_{e}-p_{z}-\sigma_{i}\right)\right] .
\end{aligned}
$$


The first-order condition reads

$$
\begin{aligned}
\frac{\mathrm{d} w_{i}}{\mathrm{~d} z_{i}^{d}}= & \sigma_{i} E_{\left(p_{e}-p_{z}\right)}^{s i}\left(P_{z_{i}^{d}}^{e}-P_{z_{i}^{d}}^{z}\right)+D_{e}-p_{z}-\left(z_{i}^{d}-z_{i}^{s}\right) P_{z_{i}^{d}}^{z}-\left[D_{e} \sum_{j} \Phi_{p_{e}}^{s j}+e_{i}^{d}-e_{i}^{s}-p_{z} \Phi_{p_{e}}^{s i}\right] P_{z_{i}^{d}}^{e} \\
= & \frac{\sigma_{i}}{\alpha}\left[\frac{\alpha b}{(\alpha+b) n}-\frac{\alpha}{n}\right]+\delta \cdot\left(\frac{n P^{e}}{\alpha}-\sum_{j} z_{j}^{d}\right)-P^{z}-[z_{i}^{d}-\underbrace{\frac{P^{z}+\sigma_{i}}{\alpha}}_{=z_{i}^{s}}) \frac{\alpha}{n} \\
& -[\delta \cdot\left(\frac{n P^{e}}{\alpha}-\sum_{j} z_{j}^{d}\right) \frac{n}{\alpha}+\underbrace{\frac{a-P^{e}}{b}-\frac{P^{e}-\left(P^{z}+\sigma_{i}\right)}{\alpha}}_{e_{i}^{d}-e_{i}^{s}}-\frac{P^{z}}{\alpha}] \frac{\alpha b}{n(\alpha+b)}=0, \\
\frac{\mathrm{d} w_{i}}{\mathrm{~d} \sigma_{i}}= & \sigma_{i} E_{\left(p_{e}-p_{z}\right)}^{s i}\left(-P_{\sigma_{i}}^{z}-1\right)-\left(z_{i}^{d}-z_{i}^{s}\right) P_{\sigma_{i}}^{z}=\frac{1}{\alpha n}\left[-(n-1) \sigma_{i}+\left(z_{i}^{d}-z_{i}^{s}\right) \alpha\right]=0 .
\end{aligned}
$$

In a symmetric Nash equilibrium $z_{i}^{s}=z_{i}^{d}$ and $e_{i}^{s}=e_{i}^{d}$ holds for all $i$ such that $\sigma_{i}=0$ for all $i$ follows from (C9). Furthermore, (C8) simplifies to

$$
\frac{\mathrm{d} w_{i}}{\mathrm{~d} z_{i}^{d}}=\delta \cdot\left(\frac{n P^{e}}{\alpha}-\sum_{j} z_{j}^{d}\right)-P^{z}-\left[\delta \cdot\left(\frac{n P^{e}}{\alpha}-\sum_{j} z_{j}^{d}\right) \frac{n}{\alpha}-\frac{P^{z}}{\alpha}\right] \frac{\alpha b}{n(\alpha+b)}=0 .
$$

We insert the price functions $P^{e}$ and $P^{z}$, set $\sum_{j} z_{j}^{d}=z_{B A U}$, and solve (C10) for $z_{B A U}$ to obtain

$$
z_{B A U}=\frac{a n^{2} \delta}{(\alpha+b)^{2}(n-1)+\alpha(\alpha+b)+\alpha \delta n^{2}} .
$$

\section{Coalition-fringe equilibrium:}

The coalition maximizes with respect to $z_{c}$ and $\sigma_{c}$ the sum of welfares

$$
\begin{aligned}
& m w_{c}=m\left\{U^{c}\left[E^{d c}\left(p_{e}\right)\right]+T^{c}\left[E^{s c}\left(p_{e}-p_{z}-\sigma_{c}\right)\right]-p_{e}\left[E^{d c}\left(p_{e}\right)-E^{s c}\left(p_{e}-p_{z}-\sigma_{c}\right)\right]\right. \\
& \left.-D\left[\sum_{j} \Phi^{s j}\left(p_{e}\right)-\left(m z_{c}+(n-m) z_{f}\right)\right]-p_{z}\left[z_{c}-\Phi^{s c}\left(p_{e}\right)+E^{s c}\left(p_{e}-p_{z}-\sigma_{c}\right)\right]\right\}(\mathrm{C}
\end{aligned}
$$

subject to

$$
\begin{aligned}
P^{z}\left(z_{c}, z_{f}, \sigma_{c}, \sigma_{f}\right) & =\frac{\alpha\left[m z_{c}+(n-m) z_{f}\right]}{n}-\frac{m \sigma_{c}+(n-m) \sigma_{f}}{n} \\
P^{e}\left(z_{c}, z_{f}\right) & =\frac{\alpha a}{\alpha+b}+\frac{\alpha b\left[m z_{c}+(n-m) z_{f}\right]}{(\alpha+b) n} .
\end{aligned}
$$

The first-order conditions are

$$
\begin{aligned}
\frac{\mathrm{d}\left(m w_{c}\right)}{\mathrm{d} z_{c}} & =m\left\{D_{e}-p_{z}-\left(z_{c}-z_{c}^{s}\right) P_{z_{c}}^{z}-\left[D_{e} \sum_{j} \Phi_{p_{e}}^{s j}+e_{i}^{d}-e_{i}^{s}-p_{z} \Phi_{p_{e}}^{s c}\right] P_{z_{c}^{d}}^{e}\right\} \\
& +\sigma_{c} E_{\left(p_{e}-p_{z}\right)}^{s c}\left(P_{z_{c}}^{e}-P_{z_{c}}^{z}\right)=0, \\
\frac{\mathrm{d}\left(m w_{c}\right)}{\mathrm{d} t_{c}} & =\sigma_{c} E_{\left(p_{e}-p_{z}\right)}^{s c}\left(-P_{\sigma_{c}}^{z}-1\right)-\left(z_{c}-z_{c}^{s}\right) P_{\sigma_{c}}^{z}=0 .
\end{aligned}
$$


The fringe countries' first-order conditions are still $(\mathrm{C} 9)$ and $(\mathrm{C} 10)$, but we replace $z_{i}^{d}$ in (C9) and (C10) by $z_{f}$ and $\sum z_{j}^{d}$ by $m z_{c}+(n-m) z_{f}$. Solving (C9), (C10), (C14) and $(\mathrm{C} 15)$ with respect to $z_{c}, z_{f}, \sigma_{c}$ and $\sigma_{f}$ yields: 


$$
\begin{aligned}
& \tilde{z}_{c}=\frac{a n^{2} \delta\left[m\left(n^{2}-1\right)+m^{2}-n(n-1)\right]}{m\left\{[n(n-1)-m(m-1)] b^{2}+[n(2 n-1)-m(m-1)] \alpha b-\left[\alpha+\left(n-m+m^{2}\right) \delta\right] n^{2} \alpha\right\}}, \\
& \tilde{\sigma}_{c}=\frac{a n^{2} \delta(m-1)(n-1) \alpha}{[n(n-1)-m(m-1)] b^{2}+[n(2 n-1)-m(m-1)] \alpha b+\left[\alpha+\left(n-m+m^{2}\right) \delta\right] n^{2} \alpha}, \\
& \tilde{z}_{f}=\frac{a n^{2} \delta[n(m-2)+1-m]}{[n(n-1)-m(m-1)] b^{2}+[n(2 n-1)-m(m-1)] \alpha b-\left[\alpha+\left(n-m+m^{2}\right) \delta\right] n^{2} \alpha}, \\
& \tilde{\sigma}_{f}=\frac{a n^{2} \delta(1-m) \alpha}{[n(n-1)-m(m-1)] b^{2}+[n(2 n-1)-m(m-1)] \alpha b+\left[\alpha+\left(n-m+m^{2}\right) \delta\right] n^{2} \alpha} .
\end{aligned}
$$

Since $\tilde{z}_{f}<0$ for all $m \geq 2$, we ignore (C8) and solve the remaining first-order conditions (C9), (C14) and (C15) for $z_{f}=0$ and obtain the coalition-fringe equilibrium deposit purchases and subsidies

$$
\begin{aligned}
z_{c} & =\frac{a n^{3}(n+m-1) \delta}{\left[n(2 n-1)-(n-1) m-m^{2}\right] b^{2}+\left[2 n(2 n-1)-(n-1) m-m^{2}\right] \alpha b+[\alpha(2 n-1)+n m(n+m-1) \delta] n \alpha}>0, \\
z_{f} & =0, \\
\sigma_{c} & =\frac{a m(n-1) n^{2} \delta \alpha}{\left[n(2 n-1)-(n-1) m-m^{2}\right] b^{2}+\left[2 n(2 n-1)-(n-1) m-m^{2}\right] \alpha b+[\alpha(2 n-1)+n m(n+m-1) \delta] n \alpha}>0, \\
\sigma_{f} & =-\frac{a m n^{2} \delta \alpha}{\left[n(2 n-1)-(n-1) m-m^{2}\right] b^{2}+\left[2 n(2 n-1)-(n-1) m-m^{2}\right] \alpha b+[\alpha(2 n-1)+n m(n+m-1) \delta] n \alpha}<0 .
\end{aligned}
$$




\section{Proof of Proposition 4:}

Inserting (C20) and (C23) into the welfare functions and calculating $\mathcal{W}^{c \sigma}(n)-\mathcal{W}^{f \sigma}(n-1)$ yields after tedious rearrangement of terms

$$
\begin{aligned}
\mathcal{W}^{c \sigma}-\mathcal{W}^{f \sigma} \gtreqless 0 \quad \Longleftrightarrow \quad & F^{\sigma}:=b^{2}(3 n-2)^{2}-\alpha b\left(5 n^{4}-18 n^{3}+6 n^{2}+10 n-5\right) \\
& -\alpha^{2}\left(5 n^{4}-18 n^{3}-2 n-1\right)-\alpha \delta(n-1)^{3} n^{2}(5 n-3) \gtreqless 0 .
\end{aligned}
$$

Proposition 4(ii) straightforwardly follows from differentiation of $F^{\sigma}$.

\section{Proof of Proposition 6:}

(i) and (ii) follow from (C20)-(C23).

(iii) Straightforward but tedious calculations yield ${ }^{25}$

$$
\begin{aligned}
m z_{c}^{\sigma}-n z_{o p t} & =-\frac{a(\alpha+b)^{2} n^{3}\left[n(2 n-1)-m(n-1)-m^{2}\right]}{\alpha\left(\alpha+b+n^{2} \delta\right) N^{\sigma}}<0, \\
z_{c}^{\sigma}-z_{c} & =\frac{a(\alpha+b)^{2}(m-1)(n-m) n^{3} \delta}{N^{\sigma}}>0, \\
\frac{\partial\left(m z_{c}^{\sigma}\right)}{\partial m} & =\frac{a(\alpha+b)^{2} n^{4}(n+2 m-1)(2 n-1) \delta}{\left(N^{\sigma}\right)^{2}}>0, \\
n e^{d \sigma}-n e_{O P T} & =\frac{a(\alpha+b) n^{3}\left[n(2 n-1)-m(n-1)-m^{2}\right]}{\left(\alpha+b+n^{2} \delta\right) N^{\sigma}}>0, \\
n e^{d \sigma}-n e^{d} & =-\frac{a \alpha(\alpha+b)(m-1)(n-m) n^{2} \delta}{N^{\sigma}}<0, \\
e^{d \sigma}-e_{c}^{s \sigma} & =\frac{a m(n-m) n^{2} \delta}{N^{\sigma}}>0, \\
\frac{\partial\left(n e^{d \sigma}\right)}{\partial m} & =\frac{a c(\alpha+b) n^{4}(n+2 m-1)(2 n-1) \delta}{\left(N^{\sigma}\right)^{2}}>0,
\end{aligned}
$$

where $N^{\sigma}:=\alpha b\left[2 n(2 n-1)-m(n-1)-m^{2}\right]+b^{2}\left[n(2 n-1)-m(n-1)-m^{2}\right]+\alpha n[\alpha(2 n-$ 1) $+m n(n+m-1) \delta]>0$.

To prove (iv) and (v), observe that

$$
B_{e_{c}^{d}}=B_{e_{f}^{d}}=p_{e}^{\sigma} \quad \Longleftrightarrow \quad e_{c}^{d \sigma}=e_{f}^{d \sigma}=e^{d \sigma} .
$$

Next, verify that

$$
\sigma_{c}>\sigma_{f} \quad \Longleftrightarrow \quad e_{c}^{s \sigma}=\frac{p_{e}^{\sigma}-p_{z}^{\sigma}-\sigma_{c}}{\alpha}<e_{f}^{s \sigma}=\frac{p_{e}^{\sigma}-p_{z}^{\sigma}-\sigma_{f}}{\alpha} .
$$

(C24) and (C25) show that fuel consumption is efficient, that fuel production is inefficient and that the coalition imports fuel. Since the coalition also imports deposits due to $z_{f}^{\sigma}=0$ it pays its import bill by exporting the consumption good. $n e^{d \sigma}>n e_{O P T}$ implies that the climate damage is excessive.

\footnotetext{
${ }^{25}$ Observe that $e_{c}^{d \sigma}=e_{f}^{d \sigma}=: e^{d \sigma}$ and $e_{c}^{d}=e_{f}^{d}=: e^{d}$.
} 